\title{
Reproductive, pathogenic and genotypic characterisation of five Meloidogyne graminicola populations from the Philippines on susceptible and resistant rice varieties
}

\author{
Ma. Teodora Nadong CABASAN ${ }^{1,2,3, *}$, Arvind KUMAR ${ }^{2}$, Stéphane BELlafiore ${ }^{4,5}$ and \\ Dirk DE WAELE ${ }^{1,2,6}$ \\ ${ }^{1}$ Laboratory of Tropical Crop Improvement, Department of Biosystems, Faculty of Bioscience Engineering, University of \\ Leuven (KU Leuven), Willem de Croylaan 42, 3001 Heverlee, Belgium \\ ${ }^{2}$ International Rice Research Institute (IRRI), DAPO Box 7777, Metro Manila, Philippines \\ ${ }^{3}$ Department of Biological Sciences, College of Arts and Sciences, University of Southern Mindanao, Kabacan 9407, \\ Cotabato, Philippines \\ ${ }^{4}$ Interactions Plantes-Microorganismes-Environnement, Institut de Recherche pour le Développement (IRD), Cirad, \\ Univ Montpellier, Montpellier, France \\ ${ }^{5}$ Laboratoire Mixte International RICE2, Agriculture Genetics Institute (AGI), Hanoi, Vietnam \\ ${ }^{6}$ Unit for Environmental Sciences and Management, North-West University, Private Bag X6001, 2520 Potchefstroom, \\ South Africa
}

Received: 29 September 2017; revised: 7 December 2017 Accepted for publication: 7 December 2017

\begin{abstract}
Summary - Five populations of Meloidogyne graminicola isolated from different rice-growing areas in the Philippines were characterised. The populations showed little phenotypic variability of second-stage juveniles and female perineal pattern. Differences in reproduction among M. graminicola populations were not observed on mature resistant Oryza glaberrima varieties 'TOG5674', 'TOG5675', 'RAM131' and 'CG14', or on susceptible $O$. sativa varieties 'IR64' and 'UPLRi-5'. In all infected rice varieties, plant growth and yield-contributing traits showed no differences among the populations. A search on M. graminicola populations from the Philippines for single-nucleotide polymorphism on the sequences of Internal Transcribed Spacer (ITS) of rDNA genes and mtDNA indicated only few points of heteroplasmy. Nematode reproduction and disease induction of the five M. graminicola populations in the Philippines exerted the same level of aggressiveness and virulence. The absence of resistance-breaking populations of M. graminicola is important for the maintenance of durability of resistance to this important rice pathogen.
\end{abstract}

Keywords - aggressiveness, heteroplasmy, ITS, morphology, mtDNA, Oryza glaberrima, Oryza sativa, root-knot nematode, virulence.

The use of a resistant or tolerant variety of an agricultural crop can be a suitable alternative for managing plant-parasitic nematodes. This is particularly relevant in farming systems with limited options for controlling nematodes, such as intensive rice-based production systems in which the efficacy of nematicides is often limited and only continuous flooding appears to be effective, which requires a constant and abundant water supply (De Waele et al., 2013).

Populations of Meloidogyne spp. may differ in their ability to reproduce and to cause damage and yield loss. Several studies have reported variability in aggressive- ness, virulence and pathogenicity on agricultural crops among populations of Meloidogyne spp. Examples are Meloidogyne javanica on tomato (Roberts \& Thomason, 1986), M. arenaria on peanut, soybean and tomato (Carpenter \& Lewis, 1991; Noe, 1992) and M. incognita on cotton (Zhou et al., 2000; Anwar \& McKenry, 2007).

Aggressiveness is a characteristic of a pathogen and it refers to the ability of a pathogen to attack and parasitise a host plant, while virulence refers to the ability of a pathogen to cause damage and/or induce disease in a host plant. The greater the aggressiveness and virulence of a pathogen, the greater is its pathogenicity (Bos

* Corresponding author, e-mail: mtncabasan@usm.edu.ph 
\& Parlevliet, 1995). In our study, aggressiveness of a nematode population is measured by the reproductive fitness (reproduction) of the nematode population on the host crop. Virulence will refer to the ability of the nematode population to cause damage and/or yield loss to the host crop. Yield is, of course, the best trait to measure the virulence of a pathogen on an agricultural crop variety.

It is common to identify varieties of an agricultural crop that are resistant to Meloidogyne spp. but resistancebreaking populations of several Meloidogyne species are challenging the use of Meloidogyne-resistant crop varieties. Virulent populations of $M$. incognita, $M$. javanica and $M$. arenaria were able to reproduce well on tomatoes 'Piersol' and 'Rossol' carrying the resistant $M i$-gene (Netscher, 1976; Berthou et al., 1989; Jarguin-Barberena et al., 1991; Castagnone-Sereno et al., 1993). A virulent population of $M$. arenaria that reproduced on susceptible tomato varieties also reproduced well on several M. arenaria-resistant tomato varieties (Prot, 1984) and the same observation, also on tomato, was made for several virulent populations of $M$. incognita (Roberts et al., 1990). Resistance-breaking populations of $M$. arenaria were also observed on tobacco (Noe, 1992), M. javanica on tomato (Eddaoudi et al., 1997) and M. incognita on cowpea (Olowe, 2010).

The rice root-knot nematode, $M$. graminicola, is one of the most damaging nematode species affecting Asian rice (Oryza sativa). Almost every rice-based production system in Asia is vulnerable to this nematode species because it is well-adapted to the wide variety of agro-ecosystems in which rice is being produced from deepwater rice to irrigated lowland and rainfed upland rice. Meloidogyne graminicola can severely reduce rice yields (Soriano et al., 2000; Padgham et al., 2004; Win et al., 2013; Patil \& Gaur, 2014). This nematode species has also been identified as a major causal agent of yield decline and even yield failure in tropical aerobic rice (Kreye et al., 2009; De Waele et al., 2013). Because of its emergence as an important pathogen of rice, the search for resistance sources to manage M. graminicola has been intensified (De Waele, pers. comm.).

Oryza glaberrima varieties resistant to M. graminicola have been reported (Plowright et al., 1999; Soriano et al., 1999; Cabasan et al., 2012, 2014). Although the mode of action of this resistance has been examined and illustrated (Jena \& Rao, 1977a, b; Cabasan et al., 2012, 2014), this resistance could be challenged with different populations of $M$. graminicola. It cannot be excluded that either more virulent $M$. graminicola populations than the populations initially used in the host response studies exist or that resistance-breaking $M$. graminicola populations may have developed by selection of pre-existing variation among different populations (Dropkin, 1988). The existence or the emergence of virulent well-reproducing nematode populations on resistant agricultural crop varieties is of great concern as this could significantly reduce the durability of the natural resistance sources (Semblat et al., 2000).

Pokharel et al. (2007) studied 33 M. graminicola populations isolated from the soil of rice-wheat fields in Nepal and observed that they were almost similar in phenotype (second-stage juvenile (J2) measurements, female perineal pattern, host range and gall shape) but that these populations showed differences in aggressiveness, measured on the basis of the nematode multiplication factor and severity of root galling on the susceptible Asian rice 'Labelle' and 'LA 110'. The authors also (partially) amplified and sequenced the internally transcribed spacer (ITS) region of the rRNA genes and found some intraspecific polymorphism but phylogenetic analyses indicated that all Nepalese $M$. graminicola populations examined formed a distinct clade with known populations of $M$. graminicola from Nepal. In 2010, Pokharel et al. reported a similar study, this time after having examined nine M. graminicola populations isolated from (Asian) rice in Nepal, India and Bangladesh, and one M. graminicola population isolated from the weed Cyperus rotundus in Florida, USA. Substantial variations in morphometrics of $\mathrm{J} 2$ among and within the populations were observed. All populations had the same host range, but the M. graminicola population isolated from $C$. rotundus in Florida did not infect the rice 'Labelle' and 'LA 110', suggesting that M. graminicola consists of more than one race/pathotype as based on the descriptions of race/pathotype by Triantaphyllou (1985) and van der Beek et al. (1999). The ITS sequences of all ten $M$. graminicola populations examined matched those of $M$. graminicola in GenBank and formed a single clade with minor variations among and within the populations. Bellafiore et al. (2015) studied 21 populations of M. graminicola isolated from the soil of rice fields in Vietnam and observed variability in the length of the body and stylet of $\mathrm{J} 2$ but without significant differences in the host range. These populations showed little intraspecific variability based on the ITS of rDNA genes but, as with the Nepalese populations (Pokharel et al., 2007), no $M$. graminicola subclades were supported by a bootstrap value higher than $65 \%$. 
Because a sound knowledge of variation in pathogenicity among populations of the same species of plantparasitic nematodes is important for management decisions and plant breeding programmes, the main objectives of our study were: $i$ ) to examine the phenotypic and genotypic variability among $M$. graminicola populations isolated from different rice-growing regions in the Philippines; and ii) to examine the pathogenicity of those $M$. graminicola populations from the Philippines on a selection of M. graminicola-resistant and susceptible rice varieties, and also to examine if (some of) these populations could break the natural resistance observed in resistant $O$. glaberima.

\section{Materials and methods}

\section{NEMATODE POPULATIONS}

The M. graminicola populations were collected from five rice-growing areas in the Philippines differing in agro-ecological conditions (Table 1). These regions represent the major rice-growing regions in the Philippines. One third to more than half of the total land area is used for agriculture and rice is the main agricultural crop. Rainfed and irrigated rice cultivation is being practised in
Batangas, Bulacan, Laguna and Tarlac, whilst rainfed rice cultivation is practised in most parts of Cotabato. The $M$. graminicola populations were isolated from infected rice plants (unknown variety) collected in Batangas, Bulacan, Cotabato, Laguna and Tarlac (Fig. 1). Rice plants showing above-ground symptoms of $M$. graminicola infection (i.e., yellowing of leaves and stunting) were carefully uprooted and the plant shoots cut off. The roots were placed in plastic bags and transported to the nematology laboratory at the International Rice Research Institute (IRRI) in the Philippines for nematode extraction. Roots were washed free of adhering soil particles and examined for the presence of hook-like galls on the root tips, typical of M. graminicola infection. Galled roots were cut into 5-10 $\mathrm{mm}$ pieces and placed in a mistifier for $48 \mathrm{~h}$ to extract J2 (Seinhorst, 1950). The nematode suspensions were examined for the presence of M. graminicola using a stereo microscope.

A culture was established for each $M$. graminicola population isolated from a single $\mathbf{J} 2$. $\mathrm{J} 2$ were handpicked and placed singly on a 5-day-old seedling of the susceptible upland rice 'UPLRi-5' planted in 30-mm-diam. transparent polystyrene (PS) tubes filled with $10 \mathrm{~g}$ of water- absorbent polymer (SAP: sand + absorbent polymer) as substrate (Reversat et al., 1999). The seedlings were main-

Table 1. Agro-ecology of the sampled areas.

\begin{tabular}{|c|c|c|c|c|c|}
\hline Area & Topography & Soil type & $\begin{array}{l}\text { Temperature } \\
\left({ }^{\circ} \mathrm{C}\right)\end{array}$ & $\begin{array}{l}\text { Annual rainfall } \\
\quad(\mathrm{mm})\end{array}$ & Season \\
\hline Batangas & $\begin{array}{l}\text { rolling terrain, small low } \\
\text { flat lands and several } \\
\text { mountains }\end{array}$ & $\begin{array}{l}\text { Sandy } \\
\text { loam to } \\
\text { clay loam }\end{array}$ & $24-28$ & 2175 & $\begin{array}{l}\text { rainy season lasts from June to } \\
\text { November; dry season lasts from January } \\
\text { to May }\end{array}$ \\
\hline Bulacan & $\begin{array}{l}\text { flat with mountains near its } \\
\text { boundaries }\end{array}$ & Clay loam & $23-32$ & 2555 & $\begin{array}{l}\text { rainy season lasts from April to } \\
\text { November, the rest of the year is dry; } \\
\text { exposed to the southwest monsoon and } \\
\text { occasional typhoons }\end{array}$ \\
\hline Cotabato & $\begin{array}{l}\text { upland ranging from level } \\
\text { to gently sloping, to } \\
\text { rolling, moderately steep to } \\
\text { very steep }\end{array}$ & $\begin{array}{l}\text { Clay loam } \\
\text { to clay }\end{array}$ & $18-30$ & 875 & $\begin{array}{l}\text { rainy and dry seasons are not } \\
\text { pronounced; rainfall is more or less } \\
\text { evenly distributed throughout the year }\end{array}$ \\
\hline Laguna & $\begin{array}{l}\text { level and gently rolling } \\
\text { plains }\end{array}$ & Clay loam & $22-34$ & 2548 & $\begin{array}{l}\text { rainfall is more or less evenly distributed } \\
\text { throughout the year but nevertheless a } \\
\text { rainy and a dry season can be recognised; } \\
\text { dry from November to April and rainy } \\
\text { during the rest of the year }\end{array}$ \\
\hline Tarlac & $\begin{array}{l}\text { flat lands and gently } \\
\text { sloping plains punctuated } \\
\text { by mountain ranges on its } \\
\text { western boundary }\end{array}$ & $\begin{array}{l}\text { Sandy } \\
\text { loam to } \\
\text { clay loam }\end{array}$ & $21-34$ & 2478 & $\begin{array}{l}\text { with two distinct seasons: a dry season } \\
\text { from November to April and a rainy } \\
\text { season from May to October }\end{array}$ \\
\hline
\end{tabular}




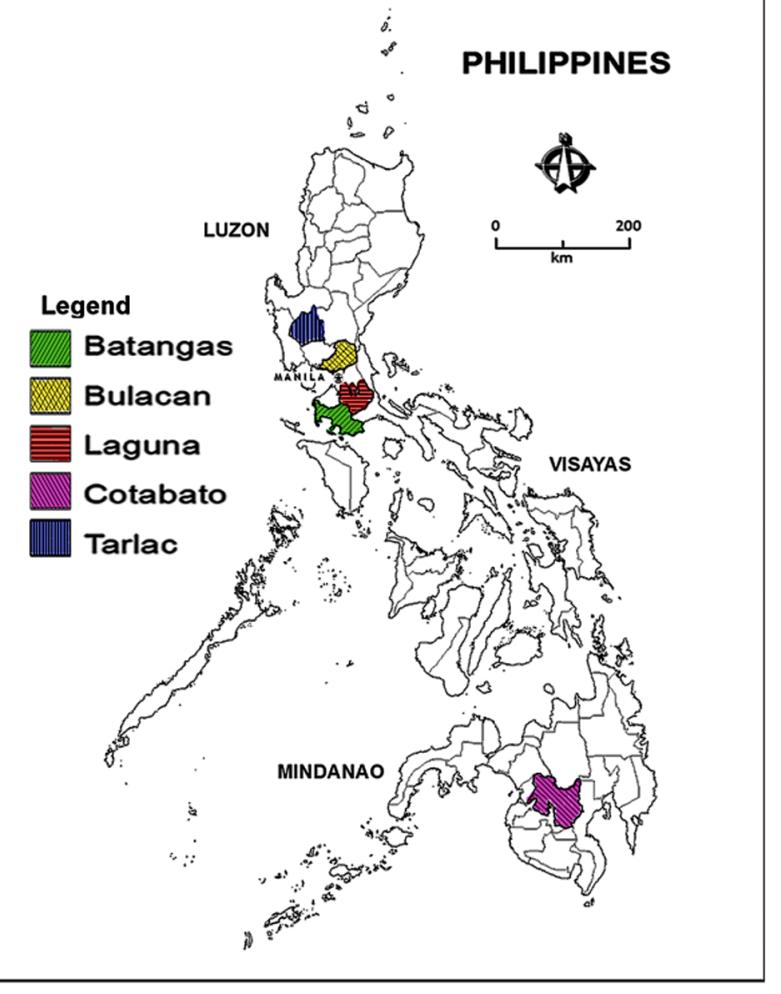

Fig. 1. Collection sites in the Philippines of the Meloidogyne graminicola populations studied.

tained in an indoor growth chamber (IGC) set at $29 / 26^{\circ} \mathrm{C}$ with a $12 \mathrm{~h}$ photoperiod. Seven days later the infected seedlings were transplanted into PS tubes each filled with $13 \mathrm{ml}$ of diluted Hoagland's solution and grown hydroponically (Reversat \& Fernandez, 2004) in the IGC for 2 weeks. To propagate the culture, J2 that developed in the rice roots grown in the hydroponic solution were extracted using the mistifier technique (Seinhorst, 1950), then an aqueous suspension containing $50 \mathrm{~J} 2$ was pipetted in 5-cm-deep holes around the base of 2-week-old seedlings of the rice 'UPLRi-5', each seedling growing in a 15-cm-diam. pot filled with a sterilised sandy loam soil. At the time of inoculation the soil in the pots was at field capacity (50\% of the soil pore volume filled with water). The five pure cultures of M. graminicola were maintained in the glasshouse on 50 'UPLRi-5' plants, each as a source of inoculum, under upland conditions, i.e., temperature above $24^{\circ} \mathrm{C}$, well-drained sandy-loamy $(52 \%$ sand, $21 \%$ loam, $27 \%$ clay), typically subjected to moisture stress, water added only when needed, with no surface water accumulation (i.e., at field capacity).
Identification of the five $M$. graminicola populations was based on the perineal pattern and morphology of the mature females, and the morphology, morphometrics and molecular characterisation of the $\mathrm{J} 2$.

\section{MORPHOLOGICAL AND MORPHOMETRIC CHARACTERISATION}

Mature M. graminicola females (egg-laying females: ELF) were handpicked from dissected galled roots of 'UPLRi-5' and placed in a drop of water on a glass slide. The morphological features of the ELF were described as observed using a light microscope. Perineal patterns were prepared by cutting the posterior end of the ELF with a sharp razor blade and cleaning the end in a solution of $45 \%$ lactic acid. The cut end was trimmed and placed on a glass slide in glycerin (Hartman \& Sasser, 1985). The perineal patterns of ten ELF per $M$. graminicola population were examined using a BX41 Olympus light microscope equipped with camera media cybernetics PL-A662 for photography.

$\mathrm{J} 2$ were also handpicked randomly from the extraction suspension, killed and fixed with dimethyl sulfoxidesalt solution (DESS). Eighteen juveniles were randomly selected per M. graminicola population and mounted on a glass slide in $100 \%$ glycerin. The morphological features observed and measured were based on the description by Mulk (1976). Measurements were taken using a BX41 light Olympus microscope equipped with a drawing tube. Measurements included were body length and maximum body width, stylet length, length from the anterior end to the end of the pharynx, tail length. The ' $a$ ' value (body length/maximum body width), ' $b$ ' value (body length/length from the anterior end to the end of the pharynx) and ' $c$ ' value (body length/tail length) were calculated for each $\mathrm{J} 2$.

\section{MOLECULAR CHARACTERISATION}

The molecular (genome) variability of the populations of M. graminicola was examined based on the comparison of partial DNA sequences of the ITS region from the rDNA (Pokharel et al., 2007) and of three mitochondrial DNA (mtDNA) sequences: $\mathrm{mtMg}-1, \mathrm{mtMg}-2$ and $\mathrm{mtMg}-3$. These mtDNA sequences use combined noncoding and coding sequences: mtMg-1 is a $1998 \mathrm{bp}$ sequence including $3^{\prime}$ part of $C O X 1$ and $5^{\prime}$ part of $N D 1$ genes; $\mathrm{mtMg}-2$ is a $1891 \mathrm{bp}$ sequence including $3^{\prime}$ part of NAD4 gene and the tRNA-Asp and finally $\mathrm{mtMg}-3$ is a 
1153 bp sequence including the ATP6 and a $5^{\prime}$ part of the ND5 genes with the tRNA-S2.

In each population $1000 \mathrm{~J} 2$ were collected and preserved in $1 \mathrm{ml}$ of DESS. Nematodes were rinsed twice in $1 \mathrm{ml}$ of sterile distilled water before DNA extraction and PCR as described by Bellafiore et al. (2015). For the nuclear DNA marker, primers rDNA2 (5'-TTGATTACGTC CCTGCCCTTT-3') and rDNA1.58s (5'-ACGAGCCCGA GTGATCCACCG-3') were used to amplify 386-bp region including a portion of the $18 \mathrm{~S}$ rDNA gene (151 bp), the complete ITS-1 and part of the 5.8S rDNA gene. PCR products were gel-purified and directly sent for sequencing using rDNA2 primer (Macrogen).

mtDNA markers were amplified by PCR in a final volume of $50 \mu \mathrm{l}$ containing $5 \mu \mathrm{l}$ of crude DNA extract, $500 \mathrm{nM}$ of each PCR primer, $200 \mathrm{mM}$ each dNTP, $50 \mathrm{mg}$ of BSA, $10 \mu \mathrm{l} 5 \times$ Phusion buffer and one unit of the proofreading enzyme, Phusion High-Fidelity DNA Polymerase (Thermo Fisher Scientific Inc.). The following PCR program was applied: $98^{\circ} \mathrm{C}$ for $30 \mathrm{~s} ; 35 \times\left(98^{\circ} \mathrm{C}\right.$, $\left.10 \mathrm{~s} ; 56^{\circ} \mathrm{C}, 30 \mathrm{~s} ; 72^{\circ} \mathrm{C}, 90 \mathrm{~s}\right) ; 72^{\circ} \mathrm{C}$ for $10 \mathrm{~min}$. The primer sequences used to amplify mtMg-1, mtMg-2 and mtMg-3 are shown in Table 2 together with the position and length of the amplified fragments. Ten independent PCR for each population and DNA marker were done. PCR products were gel-purified and directly sent for sequencing (Macrogen) using two specific primers for each amplicon. Heteroplasmy, defined as the co-existence of multiple mitochondrial DNA variants in a single nematode, was considered only if the nematode population's DNA presented at the same position with two alternative nucleotides and thus were verified in at least two independently obtained sequences (PCR and sequencing).

ITS and mtDNA sequences were aligned and manually edited with the application Mega v.6 (Tamura et al., 2013). As described in Bellafiore et al. (2015), Phylogeny.fr web platform (Dereeper et al., 2008) was used with nematode ITS and mtDNA sequences either downloaded from GenBank or generated in this study. Phylogenetic trees were generated by the maximum-likelihood method and the phylogram was bootstrapped 400 times.

\section{RICE VARIETIES}

Two $M$. graminicola-susceptible $O$. sativa varieties ('IR64' and 'UPLRi-5') and four M. graminicola-resistant O. glaberrima varieties ('TOG5674', 'TOG5675', 'CG14' and 'RAM131') were included in the pathogenicity study. The host response to $M$. graminicola infection of these rice varieties has been identified previously by Soriano et al. (1999), Plowright et al. (1999) and Cabasan et al. (2012, 2014).

The rice seeds were obtained from the seed bank of IRRI, the Philippines. 'TOG5674' and 'TOG5675' are traditional varieties from Nigeria, whilst 'CG14' and 'RAM131' are from Senegal and Mali, respectively. The African rice species $O$. glaberrima represents a valuable source of genes potentially capable of alleviating many abiotic and biotic stresses (Sarla \& Swamy, 2005) such as weed competitiveness, drought and water-lodging tolerance (Jones et al., 1997; Futakuchi et al., 2001) and

Table 2. List of mitochondrial DNA amplification and sequencing primers used in this study.

\begin{tabular}{lllrr}
\hline Primer name & Targeted DNA marker & Primer sequence $\left(5^{\prime} \rightarrow 3^{\prime}\right)$ & Primer position & Fragment length $(\mathrm{bp})$ \\
\hline Fw-mtMg-1 & mtMg-1 & TTTTGGTCATCCAGAGGTTT & 693 \\
Rev-mtMg-1 & & AGATGAAGATCGTAACCTACTAA & 2680 \\
Fw-mtMg-2 & mtMg-2 & AGCTTTAATCTTTGGTGTTCAAGT & 9041 \\
Rev-mtMg-2 & & AGTGACAGCCATTCCACAAA & 10,931 \\
Fw-mtMg-3 & mtMg-3 & TAGTCTATAGAATTCATATTTCTAAGG & 17,613 \\
Rev-mtMg-3 & & TAGGTGCAACCATAGCTTTA & 18,765 \\
SeqFwmtMg-1 & mtMg-1 & GCACCAGCTTTTGGTTTAG & 724 \\
Seq2FwmtMg-1 & mtMg-1 & TTACGTACCAGATAACTCGG & 1632 \\
SeqRevmtMg-2 & mtMg-2 & GCAGTCAAAATCGCCTCCG & 10,057 \\
Seq2RevmtMg-2 & mtMg-2 & GTTCTAAATCTACAACATATGG & 10,723 \\
SeqRevmtMg-3 & mtMg-3 & CAAAAAACAGCAATTACTCATTAC & 18,263 \\
Seq2RevmtMg-3 & mtMg-3 & GGAAACTGTGACCTTTAG & 18,727 \\
\hline
\end{tabular}

Sequences of newly developed primers and biding position of the $5^{\prime}$ extremity of these primers on the reference mitochondrial Meloidogyne graminicola coding sequence (NC_024275). The total length of the amplicon is given for the three DNA markers: mtMg-1, $\mathrm{mtMg}-2$ and $\mathrm{mtMg}-3$. 
resistance to plant-parasitic nematodes (Soriano et al., 1999; Plowright et al., 1999; De Waele, pers. comm.). 'IR64' was developed by IRRI as an improved irrigated lowland variety, whilst 'UPLRi-5' was developed in the Philippines by the University of the Philippines in Los Baños (UPLB) as an improved upland variety. Both $O$. sativa varieties have a higher yield potential (George et al., 2002) compared with the $O$. glaberrima varieties, with wide adaptability and good eating quality (Wu et al., 2005), but are moderately sensitive to drought (Wade et al., 1999).

\section{NEMATODE INOCULUM}

The nematode inoculum was prepared by uprooting 10-week-old 'UPLRi-5' plants inoculated separately with the five $M$. graminicola populations. Galled roots were washed thoroughly to remove any adhering soil particles, cut into 5-10 $\mathrm{mm}$ pieces and incubated in a mist chamber (Seinhorst, 1950). The M. graminicola J2 extracted after $24 \mathrm{~h}$ of incubation were used as the inoculum.

\section{PATHOGENICITY STUDY}

Rice seeds were pre-germinated in Petri dishes and two 5-day-old seedlings were transplanted into $20-\mathrm{cm}$ diam., 24-cm-high plastic pots each filled with $6 \mathrm{~kg}$ of a sterilised sandy loam soil. The soil was saturated at planting and at field capacity at the time of inoculation. One week later, the seedlings were thinned to one plant per pot. Two-week-old plants were inoculated with 3000 M. graminicola $\mathrm{J} 2$ by pipetting three aliquots of the same volume in three 5-cm-deep holes around the base of the seedlings. Two days later, the nematode inoculation was repeated so that the final pathogen pressure was $c a 1 \mathrm{~J} 2$ (g soil $)^{-1}$. Non-inoculated plants served as control plants.

One day after the second inoculation water was added and the soil was maintained at field capacity up to plant maturity. The rice plants were grown in the glasshouse and fertilised three times (at transplanting, and at 30 and 60 days after transplanting (DAT)) at a rate of 90-60-60 NPK kg ha ${ }^{-1}$. The experimental lay-out consisted of a randomised complete block design (RCB) in a factorial arrangement with eight replications for each rice variety, each $M$. graminicola population, inoculated and noninoculated (control) plants.

The $O$. glaberrima varieties (both inoculated and noninoculated plants) started to mature from 85 DAT onwards and at 101 DAT all the plants were harvested. The $O$. sativa varieties (both inoculated and non-inoculated plants) started to mature at 98 DAT, and at 104 DAT all the plants were harvested. At harvest, the roots were carefully uprooted, excised from the shoots, washed with tap water and the severity of root galling determined. Assessment of the severity of root galling was based on the rating scale of 0-5 (Hussey \& Janssen, 2002). After the fresh root weight of each plant was recorded, the roots were cut into $1-\mathrm{cm}$ pieces and incubated for 2 weeks in a mistifier for nematode extraction (Seinhorst, 1950). After 2 weeks in the mistifier, the nematode suspension was collected and the final number of $\mathrm{J} 2$ per root system $\left(P_{f}\right)$ counted using a stereo microscope. The nematode multiplication factor (MF) was calculated as $P_{f} / 6000(6000=$ the initial number of nematodes $\left(P_{i}\right)$ inoculated in each pot).

At harvest, the following plant growth and yield contributing traits were measured for all treatments: fresh root and shoot weight, plant height (from the soil surface to the tip of the tallest panicle), number of tillers per plant at 30 DAT, number of panicles per plant, number of spikelets per panicle, percentage of filled grains per panicle, weight of 100 grains per plant and filled grain weight per plant (adjusted to 14\% moisture content). The yield per plant was measured based on the weight of the filled grains produced per plant, not including the unfilled and partially filled grains.

\section{DATA ANALYSIS}

Nematode counts were subjected to $\log (x+1)$ transformation prior to analysis to meet the assumptions of analysis of variance (ANOVA). When these assumptions were met (i.e., normal distribution and homogeneity of variances), data were analysed using STATISTICA software (StatSoft). Factorial analysis of ANOVA was used to examine the effect of the treatments. In the case where an interaction was obtained between the two factors (nematode population and rice variety), individual comparisons were made for each rice variety separately. Tukey's HSD test $(P<0.05)$ was applied for comparisons of factor level means for nematode, plant growth and yieldcontributing trait. Dunnett's test $(P<0.05)$ was applied to compare the means of the nematode-inoculated rice varieties with the non-inoculated control plants. When the assumptions for ANOVA were met, all data were analysed using ANOVA. When the assumptions for ANOVA were not met and after transformation of the data, the nonparametric Kruskal-Wallis Rank test was used to analyse the data and mean separation was performed with the Kruskal-Wallis-Bonferroni method (combined confidence coefficient $\infty=0.05$ ). The linear relationship be- 
tween the \% yield reduction and number of $\mathrm{J} 2$ per root system was analysed using Pearson correlation analysis $(P<0.05)$.

\section{Results}

\section{MORPHOLOGICAL OBSERVATIONS}

In general, M. graminicola females of all five populations have a globular to pear-shaped body. The neck is small and the head is not distinctly set-off from the neck. The cephalic framework is inconspicuous. The stylet is small, slender and delicate, with rounded knobs sloping posteriorly. The cuticle is annulated and marked with irregular punctuations. The lateral field is obscure. The orifice of the dorsal pharyngeal gland is situated behind the stylet base. The excretory pore is conspicuous, anterior to the median pharyngeal gland, near to the stylet base. The pharynx is elongated with a cylindrical procorpus, large and rounded metacorpus, with heavily sclerotised valve. The pharyngeal gland overlaps with the intestine. The nerve ring is obscure. The two ovaries are convoluted. The vulva and anus are terminally located. The tail tip is marked with prominent striations or patterns.

Very minor variations in the perineal pattern were observed among the different populations. In general, the females of all five populations have an oval or egg-shaped perineal pattern. The dorsal arches are moderately high. No lateral lines or gaps were observed. The cuticular striae are smooth in the outer region of the oval pattern. Wavy striae converge into a tetragonal or pyramidal web near the tail remnant. All vulval lips are smooth without invaginations (Fig. 2).

No distinct differences were observed in the morphology of the $\mathrm{J} 2$ of all five populations. In general, the J2 had a vermiform body tapering towards the posterior end. The cuticle has fine annulations, about $1 \mu \mathrm{m}$ apart. The lateral field is wide, about one-third of the mid-body width. The head is rounded, and the lip region is continuous with the body and weakly sclerotised. The stylet is

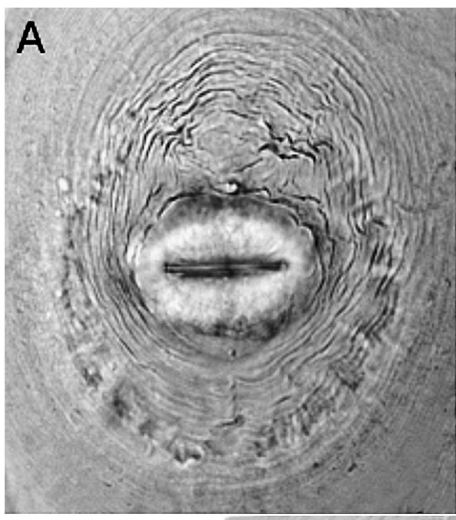

D

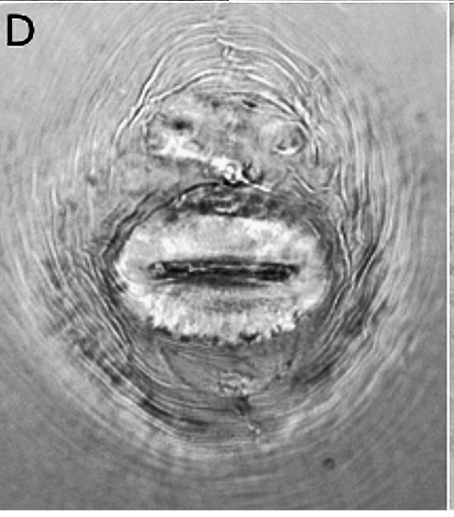

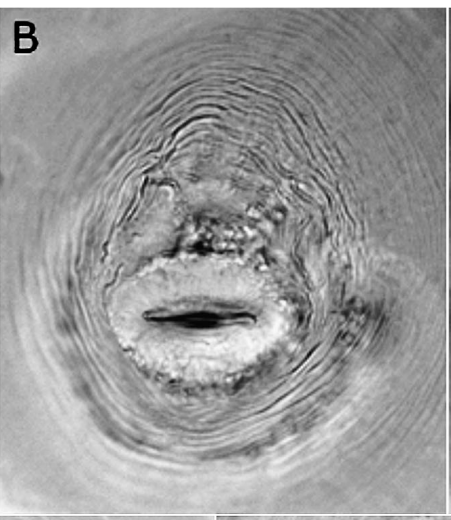
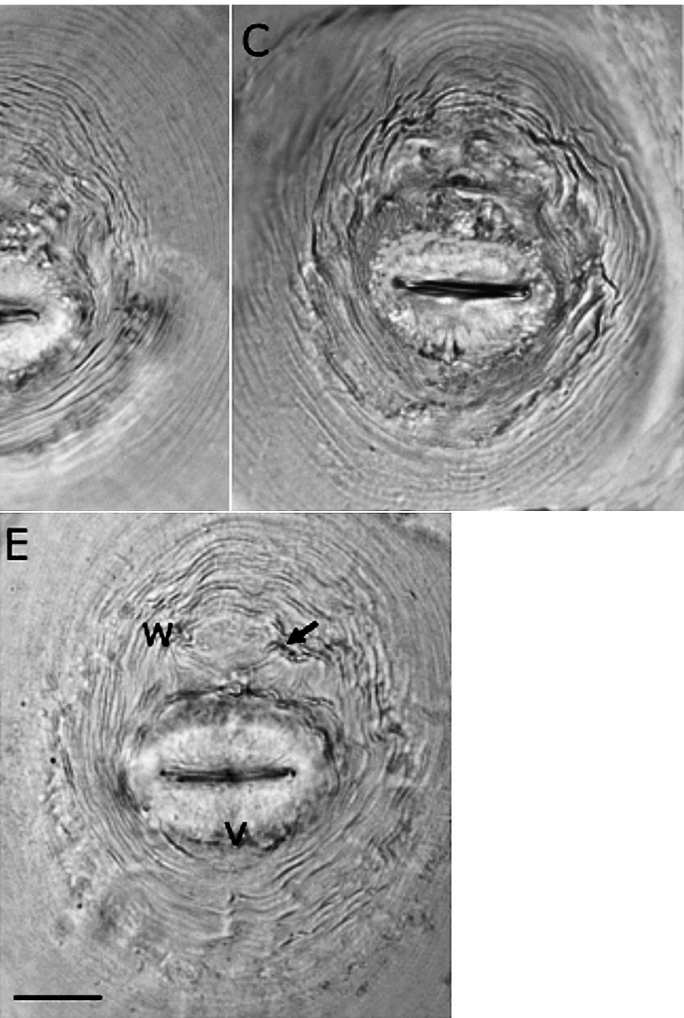

Fig. 2. Perineal patterns of mature females of Meloidogyne graminicola populations from the Philippines. A: Batangas; B: Bulacan; C: Cotabato; D: Laguna; E: Tarlac. Striae converging into a tetragonal web (w) near the tail (t) terminus dorsal to the vulva (v). (Scale bar $=20 \mu \mathrm{m}$.) 
small and delicate with rounded basal knobs. The excretory pore is situated behind the nerve ring. The median pharyngeal bulb is rounded with a prominent refractive valve and almost spherical. The tail is long and tapering uniformly with a hyaline portion and rounded tail terminus.

\section{MORPHOMETRICS}

The morphometrics of the $\mathrm{J} 2$ of all five populations are presented in Table 3 . The body length of the $\mathrm{J} 2$ ranged from 340 to $503 \mu \mathrm{m}$ (mean: $408.2 \mu \mathrm{m}$ ). The population from Batangas had the longest $(P<0.05)$ average body length $(446.6 \mu \mathrm{m})$. The length of the pharynx ranged from 84 to $158 \mu \mathrm{m}$ (mean: $116.2 \mu \mathrm{m}$ ). Among the five $M$. graminicola populations no significant differences in tail length (range 57 to $97 \mu \mathrm{m}$; mean: $80.5 \mu \mathrm{m}$ ), stylet length (range 9 to $15 \mu \mathrm{m}$; mean: $13.3 \mu \mathrm{m}$ ) and body width (range 11 to $18 \mu \mathrm{m}$; mean: $15.0 \mu \mathrm{m}$ ) were observed. The average $\mathrm{a}, \mathrm{b}$ and $\mathrm{c}$ values were significantly $(P<0.05)$ higher in the population from Batangas compared with the other four populations.

\section{MOLECULAR CHARACTERISATION}

The 386-bp nuclear rDNA region (ITS) of the $M$. graminicola populations did not show variation between populations. Based on a BLAST search, all populations have $100 \%$ identity (E. value 0.0 ) with $M$. graminicola population VN6 (GenBank accession no. KF250479). Similarly, no significant variation was found in the mitochondrial genome of the M. graminicola populations from the Philippines. The mitochondrial DNA sequences of $\mathrm{mtMg}-1$ and $\mathrm{mtMg}-3$ regions were $100 \%$ identical (E. value 0.0$)$ to the $M$. graminicola mitochondrial sequence (GenBank accession no. NC_024275.1; Besnard et al., 2014). However, the analysis on the $\mathrm{mtMg}-2$ region that includes the $3^{\prime}$ end of NAD4 gene, the complete tRNA-His gene and a non-coding region at the $5^{\prime}$ extremity of the $111 \mathrm{R}$ repeat region revealed heteroplasmy. In this 1891-bp sequence, six nucleotide sites presented heteroplasmy (transition or transversion) but no indel was detected (Table 4). For five loci, polymorphism was between nucleotides $\mathrm{A}$ and $\mathrm{T}$ (transversion) and for the sixth locus we observed a transition between $\mathrm{C}$ and $\mathrm{T}$ (therefore, respectively, encoding for $\mathrm{W}$

Table 3. Morphometrics of the second-stage juveniles (J2) of five Meloidogyne graminicola populations collected from different ricegrowing areas in the Philippines $(\mathrm{n}=18$ for each population), and populations from USA and Nepal. Values are in $\mu \mathrm{m}$ and in the form: mean \pm standard deviation (range).

\begin{tabular}{lcccccccc}
\hline $\begin{array}{l}\text { M. graminicola } \\
\text { population }\end{array}$ & Body length & Pharynx length & Tail length & Stylet length & Body width & $\mathrm{a}$ & $\mathrm{b}$ & $\mathrm{c}$ \\
\hline Batangas & $446.6 \pm 34.3 \mathrm{a}$ & $109.8 \pm 11.5 \mathrm{~b}$ & $76.9 \pm 9.2 \mathrm{a}$ & $14.2 \pm 0.8 \mathrm{a}$ & $14.2 \pm 1.4 \mathrm{a}$ & $31.6 \pm 3.6 \mathrm{a}$ & $4.1 \pm 0.6 \mathrm{a}$ & $5.9 \pm 0.7 \mathrm{a}$ \\
& $(391-503)$ & $(84-135)$ & $(59-95)$ & $(13-15)$ & $(11-17)$ & $(25.7-38.8)$ & $(3.2-5.7)$ & $(5.0-7.6)$ \\
Bulacan & $412.6 \pm 34.7 \mathrm{~b}$ & $122.8 \pm 17.8 \mathrm{a}$ & $82.0 \pm 10.6 \mathrm{a}$ & $13.0 \pm 1.3 \mathrm{a}$ & $15.5 \pm 1.9 \mathrm{a}$ & $26.9 \pm 3.4 \mathrm{~b}$ & $3.4 \pm 0.5 \mathrm{~b}$ & $5.1 \pm 0.6 \mathrm{~b}$ \\
& $(354-494)$ & $(95-158)$ & $(57-95)$ & $(10-15)$ & $(13-18)$ & $(20.8-31.8)$ & $(2.7-4.5)$ & $(4.2-6.2)$ \\
Cotabato & $386.7 \pm 35.2 \mathrm{~b}$ & $117.7 \pm 10.5 \mathrm{ab}$ & $82.8 \pm 8.8 \mathrm{a}$ & $13.1 \pm 3.1 \mathrm{a}$ & $15.4 \pm 1.4 \mathrm{a}$ & $25.3 \pm 3.4 \mathrm{~b}$ & $3.3 \pm 0.4 \mathrm{~b}$ & $4.7 \pm 0.5 \mathrm{~b}$ \\
& $(346-480)$ & $(99-129)$ & $(68-97)$ & $(11-15)$ & $(14-18)$ & $(20.5-32.4)$ & $(2.9-4.7)$ & $(4.0-5.9)$ \\
Laguna & $399.7 \pm 34.5 \mathrm{~b}$ & $112.5 \pm 13.6 \mathrm{ab}$ & $80.8 \pm 10.6 \mathrm{a}$ & $13.0 \pm 1.4 \mathrm{a}$ & $14.8 \pm 1.3 \mathrm{a}$ & $27.4 \pm 4.5 \mathrm{~b}$ & $3.6 \pm 0.4 \mathrm{~b}$ & $5.1 \pm 1.0 \mathrm{~b}$ \\
& $(340-465)$ & $(93-135)$ & $(63-97)$ & $(9-15)$ & $(11-17)$ & $(21.6-40.4)$ & $(2.9-4.1)$ & $(3.8-7.0)$ \\
Tarlac & $395.3 \pm 24.2 \mathrm{~b}$ & $118.0 \pm 12.8 \mathrm{ab}$ & $80.1 \pm 10.3 \mathrm{a}$ & $13.0 \pm 1.2 \mathrm{a}$ & $15.3 \pm 1.6 \mathrm{a}$ & $26.2 \pm 3.0 \mathrm{~b}$ & $3.4 \pm 0.5 \mathrm{~b}$ & $5.0 \pm 0.6 \mathrm{~b}$ \\
& $(346-440)$ & $(95-139)$ & $(66-94)$ & $(11-15)$ & $(12-18)$ & $(22.6-31.7)$ & $(2.9-4.6)$ & $(3.8-6.1)$ \\
USA $^{1}$ & 441.0 & 126.0 & 70.9 & 11.4 & 17.8 & 24.8 & 3.2 & 6.2 \\
& $(415-484)$ & $(112-140)$ & $(67-76)$ & $(11-12)$ & $(17-19)$ & $(22.3-27.3)$ & $(2.9-4.0)$ & $(5.5-6.7)$ \\
Nepal $^{2}$ & 450.9 & & & 11.4 & & 25.8 & 3.8 & 6.4 \\
& $(425-477)$ & & & $(10-16)$ & & $(22.3-30.5)$ & $(3.5-4.2)$ & $(5.2-8.1)$ \\
\hline
\end{tabular}

Means in the same column followed by the same letter do not differ significantly between the five M. graminicola populations according to Tukey's HSD test $(P<0.05)$.

a - body length/maximum body width.

$\mathrm{b}$ - body length/pharynx length.

c - body length/tail length.

${ }^{1}$ Golden \& Birchfield (1965); Mulk (1976).

${ }^{2}$ Pokharel et al. (2007). 
Table 4. Mitochondrial heteroplasmic single-nucleotide polymorphisms.

\begin{tabular}{|c|c|c|c|c|c|}
\hline $\begin{array}{l}\text { Position on } \\
\text { the reference } \\
\text { genome } \\
\text { (NC_024275) }\end{array}$ & Gene & $\begin{array}{c}\text { Ref } \\
\text { Base }\end{array}$ & $\begin{array}{c}\text { Var } \\
\text { Base }\end{array}$ & $\begin{array}{c}\text { IUPAC } \\
\text { nucleotide } \\
\text { code }\end{array}$ & $\begin{array}{c}\text { Nematode } \\
\text { population } \\
\text { with } \\
\text { heteroplasmy }\end{array}$ \\
\hline 577 & $N A D 4$ & $\mathrm{C}$ & $\mathrm{T}$ & Y & $\begin{array}{l}\text { Batangas, } \\
\text { Cotabato }\end{array}$ \\
\hline 1332 & N.C & A & $\mathrm{T}$ & W & $\begin{array}{c}\text { Batangas, } \\
\text { Cotabato, } \\
\text { Laguna }\end{array}$ \\
\hline 1524 & N.C & A & $\mathrm{T}$ & W & $\begin{array}{c}\text { Batangas, } \\
\text { Cotabato, } \\
\text { Tarlac }\end{array}$ \\
\hline 1534 & N.C & A & $\mathrm{T}$ & W & $\begin{array}{c}\text { Batangas, } \\
\text { Cotabato, } \\
\text { Laguna }\end{array}$ \\
\hline 1536 & N.C & A & $\mathrm{T}$ & W & $\begin{array}{c}\text { Batangas, } \\
\text { Cotabato, } \\
\text { Laguna }\end{array}$ \\
\hline 1559 & N.C & A & $\mathrm{T}$ & W & $\begin{array}{c}\text { Batangas, } \\
\text { Cotabato, } \\
\text { Laguna }\end{array}$ \\
\hline
\end{tabular}

Ref Base $=$ Reference Allele; Var Base = Variant Allele; N.C $=$ No Coding sequence.

and Y according to the IUPAC nucleotide code). Further analysis of those polymorphism sites revealed that five were in a non-coding region and one was in the NAD4 gene generating a silent mutation. The populations from Batangas and Cotabato presented a higher degree of heteroplasmy with the presence of six heteroplasmic positions while the population from Tarlac had only two heteroplasmic positions and thus in the non-coding region. None of the individuals we surveyed was homoplasmic.

\section{PATHOGENICITY STUdY}

\section{Nematode reproduction}

No significant differences in reproduction among the five populations on the resistant varieties were observed (Table 5). The highest average number of $\mathrm{J} 2$ (g root) $^{-1}$ occurred with the Batangas population on 'RAM131', while the lowest average number of $\mathrm{J} 2$ (g root) ${ }^{-1}$ was with the Bulacan population on 'TOG5674' (1,709 vs

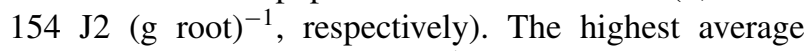
number of $\mathbf{J} 2$ (root system) $^{-1}$ was with the Laguna population on 'CG14' while the lowest average number of $\mathrm{J} 2$ (root system) $)^{-1}$ was with the Bulacan popula- tion on 'TOG5674'. The lowest MFs were observed on 'TOG5674' and 'TOG5675' (MF with one exception >1). The MF on 'CG14' and 'RAM131' were somewhat higher (Table 5).

No significant differences in reproduction among the five populations on the susceptible varieties were observed. The highest average number of $\mathrm{J} 2(\mathrm{~g} \text { root })^{-1}$ occurred with the Tarlac population on 'IR64', while the lowest average number of $\mathrm{J} 2$ (g root $)^{-1}$ occurred also with the Tarlac population on 'UPLRi-5'. The highest average number of J2 (root system) $)^{-1}$ was with the Laguna population on 'UPLRi-5', while the lowest average number of $\mathrm{J} 2$ (root system) $)^{-1}$ was with the Batangas population on 'IR64'. The MF of 'IR64' and 'UPLRi-5' ranged on average from 12.4 to 15 and from 12.4 to 19.8 , respectively.

\section{Host response}

The five $M$. graminicola populations examined in this study induced a comparable severity of root galling (in general $<3$ ) on the four resistant $O$. glaberrima varieties. The Laguna population significantly $(P<0.05)$ induced root galls on 'TOG5675' and 'RAM131'. No significant differences in severity of root galling among the five populations on the susceptible varieties were observed, ranging from 4.4 to 5.0 .

All five populations reduced the fresh root weights of the resistant varieties compared with the non-inoculated control plants but only significantly $(P<0.05)$ on 'TOG5674' and 'CG14' (Table 6). Significant differences in percentage reduction in fresh root weights among the five M. graminicola populations were not observed. All five populations also reduced the fresh shoot weights of the resistant varieties compared with the non-inoculated control plants but only significantly $(P<0.05)$ on 'TOG5674' with the Tarlac population. No significant percentage reduction in plant height of the resistant varieties was caused by any of the five $M$. graminicola populations. With a few exceptions, the percentage reduction in plant height was $<5 \%$. Compared with the noninoculated control plants, the Batangas population significantly $(P<0.05)$ reduced the fresh root weight of 'IR64', while the Batangas, Tarlac, Bulacan and Laguna populations reduced the fresh root weight of 'UPLRi5'. Compared with the non-inoculated control plants, all populations, except the Tarlac population, significantly $(P<0.05)$ reduced the fresh shoot weight of 'IR64' while the Batangas population significantly $(P<0.05)$ reduced the fresh shoot weight of 'UPLRi-5'. Compared 
Table 5. Reproduction of five populations of Meloidogyne graminicola from the Philippines on resistant $\left({ }^{\mathrm{R}}\right)$ and susceptible $\left({ }^{\mathrm{S}}\right)$ rice varieties, and severity of root galling at maturity.

\begin{tabular}{|c|c|c|c|c|c|}
\hline Rice variety & Nematode population & No. of $\mathrm{J} 2(\mathrm{~g} \text { root })^{-1}$ & No. of J2 (root system) $)^{-1}$ & Multiplication factor & Root galling index \\
\hline \multirow[t]{5}{*}{ TOG5674 } & Batangas & $277 \pm 304$ & $3905 \pm 3320$ & $0.7 \pm 0.5$ & $2.6 \pm 1.3$ \\
\hline & Bulacan & $154 \pm 111$ & $2316 \pm 2003$ & $0.4 \pm 0.3$ & $1.6 \pm 0.7$ \\
\hline & Cotabato & $227 \pm 137$ & $2889 \pm 1754$ & $0.5 \pm 0.3$ & $1.6 \pm 0.9$ \\
\hline & Laguna & $357 \pm 236$ & $4395 \pm 2887$ & $0.7 \pm 0.5$ & $3.0 \pm 1.1$ \\
\hline & Tarlac & $343 \pm 385$ & $3406 \pm 3150$ & $0.6 \pm 0.5$ & $1.8 \pm 0.9$ \\
\hline \multirow[t]{5}{*}{ TOG5675 } & Batangas & $559 \pm 544$ & $4155 \pm 3436$ & $0.7 \pm 0.8$ & $2.5 \pm 0.8 \mathrm{ab}$ \\
\hline & Bulacan & $279 \pm 269$ & $3813 \pm 3603$ & $0.6 \pm 0.6$ & $1.5 \pm 0.8 \mathrm{a}$ \\
\hline & Cotabato & $660 \pm 662$ & $6848 \pm 7337$ & $1.1 \pm 1.2$ & $2.7 \pm 0.8 \mathrm{ab}$ \\
\hline & Laguna & $567 \pm 639$ & $5475 \pm 6420$ & $0.9 \pm 1.1$ & $3.3 \pm 1.0 \mathrm{~b}$ \\
\hline & Tarlac & $379 \pm 365$ & $4636 \pm 4233$ & $0.8 \pm 0.7$ & $2.3 \pm 1.5 \mathrm{ab}$ \\
\hline \multirow[t]{5}{*}{$\mathrm{CG} 14^{\mathrm{R}}$} & Batangas & $850 \pm 761 \mathrm{ab}$ & $13845 \pm 15768$ & $2.3 \pm 2.6$ & $2.3 \pm 0.5$ \\
\hline & Bulacan & $356 \pm 358 \mathrm{a}$ & $5418 \pm 6771$ & $0.9 \pm 1.1$ & $1.4 \pm 0.5$ \\
\hline & Cotabato & $489 \pm 385 \mathrm{ab}$ & $6656 \pm 4661$ & $1.1 \pm 0.8$ & $1.8 \pm 0.7$ \\
\hline & Laguna & $901 \pm 706 b$ & $14530 \pm 9546$ & $2.2 \pm 1.7$ & $2.1 \pm 0.8$ \\
\hline & Tarlac & $545 \pm 427 \mathrm{ab}$ & $9659 \pm 9739$ & $1.6 \pm 1.6$ & $1.8 \pm 1.0$ \\
\hline \multirow[t]{5}{*}{ RAM $131^{R}$} & Batangas & $1709 \pm 1497 b$ & $12064 \pm 6336 b$ & $2.0 \pm 1.1 \mathrm{~b}$ & $1.6 \pm 0.7 \mathrm{ab}$ \\
\hline & Bulacan & $263 \pm 326 \mathrm{a}$ & $2578 \pm 2546 \mathrm{a}$ & $0.4 \pm 0.4 \mathrm{a}$ & $0.9 \pm 0.3 \mathrm{a}$ \\
\hline & Cotabato & $481 \pm 443 \mathrm{ab}$ & $3842 \pm 3096 \mathrm{ab}$ & $0.6 \pm 0.5 \mathrm{ab}$ & $1.4 \pm 0.7 \mathrm{a}$ \\
\hline & Laguna & $942 \pm 1036 \mathrm{ab}$ & $9099 \pm 10040 \mathrm{ab}$ & $1.5 \pm 1.7 \mathrm{ab}$ & $2.9 \pm 1.6 \mathrm{~b}$ \\
\hline & Tarlac & $446 \pm 519 a b$ & $4815 \pm 5598 \mathrm{ab}$ & $0.8 \pm 1.0 \mathrm{ab}$ & $1.6 \pm 0.9 \mathrm{ab}$ \\
\hline \multirow[t]{5}{*}{ IR64 ${ }^{\mathrm{S}}$} & Batangas & $5572 \pm 4076$ & $74139 \pm 57322$ & $12.4 \pm 9.6$ & $4.5 \pm 0.5$ \\
\hline & Bulacan & $5439 \pm 3560$ & $88744 \pm 51224$ & $14.8 \pm 8.5$ & $4.5 \pm 0.5$ \\
\hline & Cotabato & $5321 \pm 5043$ & $90069 \pm 59596$ & $15.0 \pm 9.9$ & $4.9 \pm 0.3$ \\
\hline & Laguna & $4775 \pm 2410$ & $84794 \pm 43672$ & $14.1 \pm 7.3$ & $4.6 \pm 0.6$ \\
\hline & Tarlac & $5611 \pm 4550$ & $89086 \pm 64544$ & $14.8 \pm 10.8$ & $4.6 \pm 0.5$ \\
\hline \multirow[t]{5}{*}{ UPLRi-5 $^{\mathrm{S}}$} & Batangas & $3483 \pm 2186$ & $90413 \pm 61119$ & $15.1 \pm 0.5$ & $4.8 \pm 0.5$ \\
\hline & Bulacan & $3444 \pm 3385$ & $102867 \pm 87062$ & $17.1 \pm 0.3$ & $4.4 \pm 1.8$ \\
\hline & Cotabato & $3166 \pm 2269$ & $109758 \pm 72598$ & $18.3 \pm 0.3$ & $4.5 \pm 0.5$ \\
\hline & Laguna & $3583 \pm 2847$ & $118909 \pm 79150$ & $19.8 \pm 0.5$ & $4.6 \pm 0.5$ \\
\hline & Tarlac & $2399 \pm 1217$ & $74374 \pm 38085$ & $12.4 \pm 0.5$ & $5.0 \pm 0.0$ \\
\hline
\end{tabular}

Number of second-stage juveniles (J2) inoculated: 6000 plant $^{-1}$.Data are means \pm standard deviation $(\mathrm{n}=8)$. Means of the same rice variety followed by the same letter are not significantly different according to Tukey's HSD test $(P<0.05)$. Multiplication Factor $=$ number of $\mathrm{J} 2$ per root system/6000 $\mathrm{J} 2$.

with the non-inoculated control plants, all populations significantly $(P<0.05)$ reduced the plant height of 'UPLRi-5'.

No significant differences were observed on the yieldcontributing traits and yield of the plants inoculated with each of the five M. graminicola populations (Tables 7-9). All five populations reduced the number of tillers per plant, number of panicles per plant, and number of spikelets per panicle of the resistant varieties compared with the non-inoculated control plants but only the Batangas, Cotabato, Laguna and Tarlac populations caused a significant $(P<0.05)$ reduction in the number of tillers per plant on 'TOG5674' and the Tarlac population in the number of panicles per plant. Although the five $M$. graminicola populations caused reductions in number of spikelets per panicle on the susceptible varieties compared with the non-inoculated control plants, these percentage reductions were only significant $(P<0.05)$ for the Cotabato population on 'IR64' and the Batangas population on 'UPLRi-5'.

Although all five $M$. graminicola populations mostly reduced the percentage of filled grains per panicle, filled grain weight per plant and weight of 100 grains per plant compared with the non-inoculated control plants of both the resistant and the susceptible varieties, no significant reductions were observed, with the exception of 
Table 6. Fresh root and shoot weight, and plant height at maturity of resistant $\left({ }^{\mathrm{R}}\right)$ and susceptible $\left({ }^{\mathrm{S}}\right)$ rice varieties inoculated with five different populations of Meloidogyne graminicola from the Philippines, and percentage reduction when compared with non-inoculated control plants.

\begin{tabular}{|c|c|c|c|c|c|c|c|}
\hline \multirow[t]{2}{*}{ Rice variety } & \multirow[t]{2}{*}{ Nematode population } & \multicolumn{2}{|c|}{ Fresh root weight } & \multicolumn{2}{|c|}{ Fresh shoot weight } & \multicolumn{2}{|c|}{ Plant height at maturity } \\
\hline & & $\mathrm{g}$ & Reduction (\%) & $\mathrm{g}$ & Reduction (\%) & $\mathrm{cm}$ & Reduction $(\%)$ \\
\hline \multirow[t]{6}{*}{ TOG5674 ${ }^{\mathrm{R}}$} & Batangas & $16.4 \mathrm{Aa}$ & -24.1 & $123.9 \mathrm{Aa}$ & -20.8 & 129.8 & 0.7 \\
\hline & Bulacan & $14.5 \mathrm{Aa}$ & -32.9 & $148.1 \mathrm{Aa}$ & -5.3 & 125.0 & -3.0 \\
\hline & Cotabato & $13.6 \mathrm{Aa}$ & -37.2 & $124.5 \mathrm{Aa}$ & -20.4 & 126.2 & -2.1 \\
\hline & Laguna & $12.9 \mathrm{Aa}$ & -40.4 & $113.9 \mathrm{Aa}$ & -27.2 & 129.4 & 0.4 \\
\hline & Tarlac & $12.1 \mathrm{Aa}$ & -44.1 & $110.0 \mathrm{Ab}$ & -29.7 & 128.5 & -0.3 \\
\hline & Non-inoculated & $21.6 \mathrm{~b}$ & 0.0 & $156.4 \mathrm{a}$ & 0.0 & 128.9 & 0.0 \\
\hline \multirow[t]{6}{*}{ TOG5675 } & Batangas & 12.4 & -21.7 & 100.1 & -27.0 & 114.0 & -6.1 \\
\hline & Bulacan & 13.3 & -15.9 & 105.6 & -23.0 & 124.4 & 2.4 \\
\hline & Cotabato & 12.0 & -24.1 & 107.7 & -21.5 & 123.7 & 1.9 \\
\hline & Laguna & 11.6 & -26.8 & 103.0 & -24.9 & 119.8 & -1.4 \\
\hline & Tarlac & 13.2 & -16.9 & 123.2 & -10.2 & 123.5 & 1.6 \\
\hline & Non-inoculated & 15.9 & 0.0 & 137.2 & 0.0 & 121.5 & 0.0 \\
\hline \multirow[t]{6}{*}{$\mathrm{CG} 14^{\mathrm{R}}$} & Batangas & $16.0 \mathrm{Aa}$ & -22.6 & 122.1 & -6.2 & 135.0 & 1.8 \\
\hline & Bulacan & $14.8 \mathrm{Aa}$ & -28.2 & 93.4 & -28.2 & 126.6 & -4.5 \\
\hline & Cotabato & $14.9 \mathrm{Aa}$ & -27.6 & 110.1 & -15.4 & 135.9 & 2.5 \\
\hline & Laguna & 17.2 Aa & -16.6 & 113.4 & -12.8 & 130.9 & -1.3 \\
\hline & Tarlac & $14.5 \mathrm{Aa}$ & -29.6 & 112.9 & -13.2 & 137.4 & 3.6 \\
\hline & Non-inoculated & $20.6 \mathrm{~b}$ & 0.0 & 130.1 & 0.0 & 132.6 & 0.0 \\
\hline \multirow[t]{6}{*}{$\mathrm{RAM} 131^{\mathrm{R}}$} & Batangas & 7.6 & -31.5 & 93.5 & -3.9 & 102.3 & -2.8 \\
\hline & Bulacan & 9.3 & -16.2 & 88.9 & -9.0 & 103.9 & -1.2 \\
\hline & Cotabato & 9.2 & -17.1 & 79.7 & -18.4 & 87.4 & -16.9 \\
\hline & Laguna & 8.1 & -27.0 & 74.1 & -24.2 & 107.4 & 2.1 \\
\hline & Tarlac & 10.6 & -4.5 & 85.9 & -12.1 & 82.7 & -21.4 \\
\hline & Non-inoculated & 11.1 & 0.0 & 97.7 & 0.0 & 105.2 & 0.0 \\
\hline \multirow[t]{6}{*}{ IR64 ${ }^{S}$} & Batangas & $13.3 \mathrm{Aa}$ & -48.0 & 85.1 Aa & -41.8 & 70.5 & -11.6 \\
\hline & Bulacan & $18.6 \mathrm{Ab}$ & -27.2 & $100.8 \mathrm{Aa}$ & -31.1 & 68.8 & -13.8 \\
\hline & Cotabato & $20.5 \mathrm{Ab}$ & -19.7 & $100.7 \mathrm{Aa}$ & -31.2 & 75.2 & -5.8 \\
\hline & Laguna & $18.9 \mathrm{Ab}$ & -26.0 & $90.1 \mathrm{Aa}$ & -38.4 & 64.4 & -19.3 \\
\hline & Tarlac & $18.1 \mathrm{Ab}$ & -29.0 & $105.3 \mathrm{~b}$ & -28.0 & 68.1 & -14.6 \\
\hline & Non-inoculated & $25.5 \mathrm{~b}$ & 0.0 & $146.3 \mathrm{~b}$ & 0.0 & 79.7 & 0.0 \\
\hline \multirow[t]{6}{*}{$\mathrm{UPLRi}^{-5^{\mathrm{S}}}$} & Batangas & $26.5 \mathrm{Aa}$ & -40.5 & $156.4 \mathrm{Aa}$ & -25.6 & $114.8 \mathrm{Aa}$ & -7.9 \\
\hline & Bulacan & $34.6 \mathrm{Aa}$ & -22.3 & $187.3 \mathrm{Ab}$ & -10.9 & $106.7 \mathrm{Aa}$ & -14.5 \\
\hline & Cotabato & $37.4 \mathrm{Ab}$ & -16.0 & $190.1 \mathrm{Ab}$ & -9.6 & $109.0 \mathrm{Aa}$ & -12.6 \\
\hline & Laguna & $36.0 \mathrm{Aa}$ & -19.1 & $172.8 \mathrm{Ab}$ & -17.8 & $102.4 \mathrm{Aa}$ & -17.9 \\
\hline & Tarlac & $33.2 \mathrm{Aa}$ & -25.4 & $160.1 \mathrm{Ab}$ & -23.9 & $105.8 \mathrm{Aa}$ & -15.1 \\
\hline & Non-inoculated & $44.5 \mathrm{~b}$ & 0.0 & $210.3 \mathrm{~b}$ & 0.0 & $124.7 \mathrm{~b}$ & 0.0 \\
\hline
\end{tabular}

Means of the same rice varieties followed by the same uppercase letter are not significantly different among the five $M$. graminicola populations according to Tukey's HSD test $(P<0.05)$. $(\mathrm{n}=8)$.

Means of the same rice varieties followed by the same lowercase letter are not significantly different from the non-inoculated control plants according to Dunnett's test $(P<0.05)$. $(\mathrm{n}=8)$.

the Batangas population in 'TOG5675' and 'RAM131'. A high reduction in filled grain weight per plant of 'IR64' was caused by the Batangas, Cotabato and Laguna populations, while all five populations caused a high reduction in filled grain weight per plant on 'UPLRi-5'.

The percentage yield reduction was positively correlated with the number of $\mathrm{J} 2$ per root system of the rice 
Table 7. Yield component parameters of resistant $\left({ }^{\mathrm{R}}\right)$ and susceptible $\left({ }^{\mathrm{S}}\right)$ rice varieties inoculated with five different populations of Meloidogyne graminicola from the Philippines, and percentage reduction when compared with non-inoculated control plants.

\begin{tabular}{|c|c|c|c|c|c|c|c|}
\hline \multirow[t]{2}{*}{ Rice variety } & \multirow[t]{2}{*}{ Nematode population } & \multicolumn{2}{|c|}{$\begin{array}{c}\text { Number of tillers } \\
\text { per plant }\end{array}$} & \multicolumn{2}{|c|}{$\begin{array}{c}\text { Number of panicles } \\
\text { per plant }\end{array}$} & \multicolumn{2}{|c|}{$\begin{array}{l}\text { Number of spikelets } \\
\text { per panicle }\end{array}$} \\
\hline & & $\mathrm{n}$ & Reduction (\%) & $\mathrm{n}$ & Reduction (\%) & $\mathrm{n}$ & Reduction (\%) \\
\hline \multirow[t]{6}{*}{ TOG5674 ${ }^{\mathrm{R}}$} & Batangas & $9.9 \mathrm{Aa}$ & -36.9 & $19.6 \mathrm{Ab}$ & -13.3 & 80.8 & -2.7 \\
\hline & Bulacan & $13.6 \mathrm{Aa}$ & -13.4 & $19.9 \mathrm{Aa}$ & -11.9 & 78.1 & -5.9 \\
\hline & Cotabato & $11.0 \mathrm{Aa}$ & -29.9 & $18.4 \mathrm{Ab}$ & -18.6 & 77.1 & -7.1 \\
\hline & Laguna & $10.7 \mathrm{Aa}$ & -31.8 & $16.0 \mathrm{Ab}$ & -29.1 & 78.0 & -6.0 \\
\hline & Tarlac & $9.7 \mathrm{Aa}$ & -38.2 & $15.5 \mathrm{Aa}$ & -31.3 & 78.3 & -5.7 \\
\hline & Non-inoculated & $15.7 \mathrm{~b}$ & 0.0 & $22.6 \mathrm{~b}$ & 0.0 & 83.0 & 0.0 \\
\hline \multirow[t]{6}{*}{ TOG5675 ${ }^{\mathrm{R}}$} & Batangas & 8.7 & -22.3 & 16.0 & -28.4 & 59.4 & -14.5 \\
\hline & Bulacan & 8.9 & -20.5 & 17.4 & -22.2 & 66.8 & -3.9 \\
\hline & Cotabato & 8.4 & -25.0 & 20.9 & -6.6 & 61.8 & -11.0 \\
\hline & Laguna & 9.9 & -11.6 & 20.8 & -7.1 & 60.6 & -12.7 \\
\hline & Tarlac & 9.4 & -16.1 & 18.9 & -15.5 & 69.7 & 0.3 \\
\hline & Non-inoculated & 11.2 & 0.0 & 22.3 & 0.0 & 69.4 & 0.0 \\
\hline \multirow[t]{6}{*}{$\mathrm{CG} 14^{\mathrm{R}}$} & Batangas & 8.5 & -25.4 & 19.4 & -0.6 & 98.1 & -3.1 \\
\hline & Bulacan & 7.9 & -30.7 & 14.3 & -26.9 & 96.0 & -5.2 \\
\hline & Cotabato & 8.4 & -26.3 & 16.9 & -13.5 & 102.9 & 1.7 \\
\hline & Laguna & 8.1 & -28.9 & 17.0 & -12.8 & 99.3 & -1.9 \\
\hline & Tarlac & 6.4 & -43.9 & 17.6 & -9.6 & 90.9 & -10.2 \\
\hline & Non-inoculated & 11.4 & 0.0 & 19.5 & 0.0 & 101.3 & 0.0 \\
\hline \multirow[t]{6}{*}{ RAM131 ${ }^{\mathrm{R}}$} & Batangas & 8.7 & -29.3 & 7.3 & 4.3 & 55.8 & -5.6 \\
\hline & Bulacan & 12.0 & -2.4 & 7.7 & 10.0 & 53.6 & -9.4 \\
\hline & Cotabato & 12.7 & 3.3 & 5.7 & -18.6 & 41.2 & -30.3 \\
\hline & Laguna & 9.5 & -22.8 & 8.8 & 25.7 & 43.6 & -26.3 \\
\hline & Tarlac & 10.0 & -18.7 & 5.3 & -25.0 & 35.6 & -39.9 \\
\hline & Non-inoculated & 12.3 & 0.0 & 7.0 & 0.0 & 59.1 & 0.0 \\
\hline \multirow[t]{6}{*}{ IR64 ${ }^{\mathrm{S}}$} & Batangas & 11.9 & -16.8 & 13.0 & -34.6 & $74.4 \mathrm{Ab}$ & -30.8 \\
\hline & Bulacan & 9.5 & -33.6 & 16.3 & -18.0 & $75.4 \mathrm{Ab}$ & -29.8 \\
\hline & Cotabato & 11.4 & -20.3 & 14.9 & -25.0 & $66.9 \mathrm{Aa}$ & -37.8 \\
\hline & Laguna & 10.8 & -24.5 & 12.9 & -35.2 & $71.8 \mathrm{Ab}$ & -33.2 \\
\hline & Tarlac & 12.8 & -10.5 & 16.3 & -18.2 & $83.1 \mathrm{Ab}$ & -22.6 \\
\hline & Non-inoculated & 14.3 & 0.0 & 19.9 & 0.0 & $107.4 \mathrm{~b}$ & 0.0 \\
\hline \multirow[t]{6}{*}{ UPLRi- $5^{\mathrm{S}}$} & Batangas & 8.0 & -20.8 & 10.5 & -30.6 & $109.7 \mathrm{Aa}$ & -31.4 \\
\hline & Bulacan & 9.8 & -3.0 & 13.5 & -10.7 & $133.9 \mathrm{Ab}$ & -16.2 \\
\hline & Cotabato & 9.5 & -5.9 & 13.6 & -9.9 & $137.9 \mathrm{Ab}$ & -13.7 \\
\hline & Laguna & 8.1 & -19.8 & 13.6 & -9.9 & $121.4 \mathrm{Ab}$ & -24.1 \\
\hline & Tarlac & 9.4 & -6.9 & 13.5 & -10.7 & $119.6 \mathrm{Ab}$ & -25.1 \\
\hline & Non-inoculated & 10.1 & 0.0 & 15.1 & 0.0 & $159.8 \mathrm{~b}$ & 0.0 \\
\hline
\end{tabular}

Means of the same rice varieties followed by the same uppercase letter are not significantly different among the five M. graminicola populations according to Tukey's HSD test $(P<0.05)$. $(\mathrm{n}=8)$.

Means of the same rice varieties followed by the same lowercase letter are not significantly different from the non-inoculated control plants according to Dunnett's test $(P<0.05)$. $(\mathrm{n}=8)$.

genotypes $(P<0.05, r=0.80)$. Figure 3 shows the percentage yield reduction in M. graminicola-infected resistant and susceptible rice varieties when compared with non-inoculated control plants. On average, the four resis- tant rice varieties suffered a yield reduction of $18.4 \%$. Among the resistant varieties, the highest average percentage yield reduction was always caused by the Batangas population. The highest percentage yield reduction 
Table 8. Yield-contributing traits data of resistant $\left({ }^{\mathrm{R}}\right)$ and susceptible $\left({ }^{\mathrm{S}}\right)$ rice varieties inoculated with five different populations of Meloidogyne graminicola populations (6000 second-stage juveniles plant ${ }^{-1}$ ) from the Philippines, and percentage change when compared with no-inoculated control plants.

\begin{tabular}{|c|c|c|c|c|c|c|c|}
\hline \multirow[t]{2}{*}{ Rice genotype } & \multirow[t]{2}{*}{ Nematode population } & \multicolumn{2}{|c|}{$\begin{array}{l}\text { Percentage filled } \\
\text { grains per panicle }\end{array}$} & \multicolumn{2}{|c|}{$\begin{array}{l}\text { Weight of } 100 \\
\text { grains per plant }\end{array}$} & \multicolumn{2}{|c|}{$\begin{array}{c}\text { Filled grain } \\
\text { weight per plant }\end{array}$} \\
\hline & & $(\%)$ & $\%$ change & $(\mathrm{g})$ & $\%$ change & (g) & $\%$ change \\
\hline \multirow[t]{6}{*}{ TOG5674 ${ }^{\mathrm{R}}$} & Batangas & 70.9 & -8.3 & 2.3 & 15.6 & 9.4 & -22.5 \\
\hline & Bulacan & 73.1 & -5.4 & 2.2 & 9.1 & 12.1 & 0.4 \\
\hline & Cotabato & 77.4 & 0.1 & 2.2 & 13.4 & 10.7 & -11.5 \\
\hline & Laguna & 74.7 & -3.4 & 2.0 & -0.4 & 9.9 & -17.8 \\
\hline & Tarlac & 75.5 & -2.3 & 2.0 & 2.9 & 10.6 & -12.2 \\
\hline & Non-inoculated & 77.3 & 0.0 & 2.0 & 0.0 & 12.1 & 0.0 \\
\hline \multirow[t]{6}{*}{ TOG5675 ${ }^{\mathrm{R}}$} & Batangas & 61.5 & -15.2 & 1.9 & -11.6 & $7.2 \mathrm{Aa}$ & -35.8 \\
\hline & Bulacan & 64.2 & -11.5 & 2.0 & -7.7 & $9.7 \mathrm{Ab}$ & -13.7 \\
\hline & Cotabato & 79.4 & 9.4 & 2.2 & 3.0 & $13.8 \mathrm{Ab}$ & 23.4 \\
\hline & Laguna & 75.7 & 4.3 & 2.3 & 4.0 & $8.9 \mathrm{Ab}$ & -20.3 \\
\hline & Tarlac & 67.8 & -6.6 & 2.2 & -0.6 & $11.0 \mathrm{Ab}$ & -1.6 \\
\hline & Non-inoculated & 72.6 & 0.0 & 2.2 & 0.0 & $11.2 \mathrm{~b}$ & 0.0 \\
\hline \multirow[t]{6}{*}{$\mathrm{CG} 14^{\mathrm{R}}$} & Batangas & 65.3 & -4.7 & 2.0 & -1.7 & 11.2 & -13.7 \\
\hline & Bulacan & 60.7 & -11.4 & 2.0 & -0.9 & 11.5 & -11.7 \\
\hline & Cotabato & 72.9 & 6.5 & 2.2 & 7.6 & 14.1 & 8.2 \\
\hline & Laguna & 66.5 & -2.9 & 1.9 & -7.0 & 12.0 & -7.5 \\
\hline & Tarlac & 71.5 & 4.4 & 2.1 & 4.5 & 11.7 & -9.8 \\
\hline & Non-inoculated & 68.5 & 0.0 & 2.0 & 0.0 & 13.0 & 0.0 \\
\hline \multirow[t]{6}{*}{ RAM $131^{R}$} & Batangas & 31.5 & -35.6 & 1.5 & -2.7 & $2.2 \mathrm{Aa}$ & -58.9 \\
\hline & Bulacan & 38.6 & -21.1 & 1.4 & -10.7 & $3.8 \mathrm{Ab}$ & -30.9 \\
\hline & Cotabato & 24.8 & -49.3 & 1.6 & 3.1 & $4.3 \mathrm{Ab}$ & -21.2 \\
\hline & Laguna & 27.5 & -43.8 & 1.4 & -7.4 & $5.5 \mathrm{Ab}$ & 1.5 \\
\hline & Tarlac & 35.4 & -27.6 & 1.6 & 1.1 & $5.1 \mathrm{Ab}$ & -5.5 \\
\hline & Non-inoculated & 48.9 & 0.0 & 1.6 & 0.0 & $5.4 \mathrm{~b}$ & 0.0 \\
\hline \multirow[t]{6}{*}{ IR64 ${ }^{S}$} & Batangas & 65.0 & -10.7 & 1.9 & -3.3 & $4.9 \mathrm{Aa}$ & -66.7 \\
\hline & Bulacan & 62.4 & -14.2 & 2.0 & 1.7 & $7.7 \mathrm{Ab}$ & -47.0 \\
\hline & Cotabato & 62.6 & -14.0 & 1.9 & -2.2 & $5.7 \mathrm{Aa}$ & -61.0 \\
\hline & Laguna & 62.7 & -13.8 & 1.9 & -2.0 & $4.5 \mathrm{Aa}$ & -69.2 \\
\hline & Tarlac & 68.4 & -6.0 & 2.0 & -0.3 & $7.7 \mathrm{Ab}$ & -47.0 \\
\hline & Non-inoculated & 72.8 & 0.0 & 2.0 & 0.0 & $14.6 \mathrm{~b}$ & 0.0 \\
\hline \multirow[t]{6}{*}{ UPLRi-5 $^{\text {S }}$} & Batangas & 62.5 & -10.8 & 2.1 & -6.8 & $10.1 \mathrm{Aa}$ & -49.3 \\
\hline & Bulacan & 56.7 & -19.1 & 2.1 & -5.5 & $9.8 \mathrm{Aa}$ & -50.8 \\
\hline & Cotabato & 59.5 & -15.1 & 2.0 & -8.2 & $11.7 \mathrm{Aa}$ & -41.3 \\
\hline & Laguna & 57.4 & -18.1 & 2.1 & -5.1 & $11.3 \mathrm{Aa}$ & -43.1 \\
\hline & Tarlac & 59.2 & -15.5 & 2.1 & -5.7 & $12.7 \mathrm{Aa}$ & -36.3 \\
\hline & Non-inoculated & 70.1 & 0.0 & 2.2 & 0.0 & $19.9 \mathrm{~b}$ & 0.0 \\
\hline
\end{tabular}

Means of the same rice varieties followed by the same uppercase letter are not significantly different among the five M. graminicola populations according to Tukey's HSD test $(P<0.05)$. $(\mathrm{n}=8)$.

Means of the same rice varieties followed by the same lowercase letter are not significantly different from the non-inoculated control plants according to Dunnett's test $(P<0.05)$. $(\mathrm{n}=8)$.

by this population was observed on 'RAM131' (58.9\%; $P<0.05)$ and on 'TOG5675' (35.8\%; $P<0.05)$. Among the resistant rice varieties, the lowest average per- centage yield reductions were caused by each of the other four M. graminicola populations. On average, the two susceptible rice varieties suffered a yield reduction of $51.2 \%$. 
Table 9. Average fresh root weight and average percentage change in plant growth data and yield-contributing traits of resistant $\left({ }^{\mathrm{R}}\right)$ and susceptible $\left({ }^{S}\right)$ rice varieties inoculated with five Meloidogyne graminicola populations (6000 second-stage juveniles plant ${ }^{-1}$ ) from the Philippines compared with non-inoculated control plants for each rice variety, and for the resistant and susceptible varieties combined.

\begin{tabular}{|c|c|c|c|c|c|c|c|c|c|c|}
\hline Rice genotype & $\begin{array}{c}\text { Average } \\
\text { fresh root } \\
\text { weight }(\mathrm{g})\end{array}$ & $\begin{array}{c}\text { Fresh root } \\
\text { weight }\end{array}$ & $\begin{array}{c}\text { Fresh } \\
\text { shoot } \\
\text { weight }\end{array}$ & $\begin{array}{c}\text { Plant } \\
\text { height at } \\
\text { maturity }\end{array}$ & $\begin{array}{c}\text { Number of } \\
\text { tillers per } \\
\text { plant }\end{array}$ & $\begin{array}{l}\text { Number of } \\
\text { panicles } \\
\text { per plant }\end{array}$ & $\begin{array}{l}\text { Number of } \\
\text { spikelets } \\
\text { per panicle }\end{array}$ & $\begin{array}{l}\text { Percentage } \\
\text { filled } \\
\text { grains per } \\
\text { panicle }\end{array}$ & $\begin{array}{c}\text { Weight of } \\
100 \text { grains } \\
\text { per plant }\end{array}$ & $\begin{array}{c}\text { Filled } \\
\text { grain } \\
\text { weight per } \\
\text { plant }\end{array}$ \\
\hline TOG5674 ${ }^{\mathrm{R}}$ & 26.1 & -35.8 & -20.7 & -1.8 & -30.1 & -20.9 & -5.5 & -4.9 & -0.4 & -16.0 \\
\hline TOG5675 & 15.9 & -21.1 & -21.3 & -3.8 & -19.1 & -15.9 & -10.5 & -11.1 & -6.7 & -17.8 \\
\hline $\mathrm{CG} 14^{\mathrm{R}}$ & 20.6 & -24.9 & -15.2 & -2.9 & -31.1 & -12.7 & -5.1 & -6.3 & -6.7 & -10.7 \\
\hline RAM131 ${ }^{\mathrm{R}}$ & 11.1 & -19.3 & -13.5 & -10.6 & -18.3 & -21.8 & -22.3 & -35.5 & -6.9 & -29.1 \\
\hline IR64 $^{\mathrm{S}}$ & 25.5 & -30.0 & -34.1 & -13.0 & -21.1 & -26.2 & -30.8 & -11.7 & -2.0 & -58.2 \\
\hline UPLRi-5 $^{\mathrm{S}}$ & 44.5 & -24.7 & -17.6 & -13.6 & -11.3 & -14.4 & -22.1 & -15.7 & -6.3 & -44.2 \\
\hline Resistant & 18.4 & -25.3 & -17.7 & -4.8 & -24.6 & -17.8 & -10.9 & -14.4 & -5.1 & -18.4 \\
\hline Susceptible & 35.0 & -27.3 & -25.8 & -13.3 & -16.2 & -20.3 & -26.5 & -13.7 & -4.1 & -51.2 \\
\hline
\end{tabular}

For both susceptible varieties, the percentage yield reductions were significantly $(P<0.05)$ different compared with the non-inoculated control plants. The percentage yield reduction was on average higher on 'IR64' (58.2\%) compared with 'UPLRi-5' (44.2\%). On 'IR64', the highest percentage yield reduction was caused by the Laguna population (69.2\%) closely followed by the Batangas population (66.7\%), and the lowest percentage yield reduction was by the Bulacan and Tarlac populations (both 47\%). On 'UPLRi-5', the highest percentage yield reduction was caused by the Bulacan population $(50.8 \%)$ closely followed by the Batangas population $(49.3 \%)$, and the lowest by the Tarlac population $(36.3 \%)$.

For both the resistant and susceptible rice varieties, on average, fresh root and shoot weight were more affected among the plant growth traits compared with plant height (Table 9). Among the resistant varieties, on average, the number of tillers per plant was the most affected yield component (24.6\%) while the weight of 100 grains per plant was the least affected yield component $(5.1 \%)$. Between the two susceptible varieties, on average, filled grain weight per plant was the most affected yield component $(51.2 \%)$ while the weight of 100 grains per plant weight was the least affected yield component $(4.1 \%)$.

\section{Discussion}

The five M. graminicola populations collected from rice-growing areas in the Philippines varying in agro- ecological conditions showed comparable morphology, morphometrics and molecular characteristics. The morphology of the $\mathrm{J} 2$ of the five M. graminicola populations examined was similar to the descriptions by Golden \& Birchfield (1965), Mulk (1976) and Pokharel et al. (2007). The $\mathrm{J} 2$ measurements were within the range of the measurements reported so far for this nematode species (Mulk, 1976) but with interspecific variations among the five populations based on body length and stylet length, and among different $M$. graminicola populations in the USA (Golden \& Birchfield, 1965), Nepal (Pokharel et al., 2007) and Vietnam (Bellafiore et al., 2015). The perineal pattern of the M. graminicola females were, with some minor variability, similar to the published perineal patterns of this nematode species (Mulk, 1976; Pokharel et al., 2007). Phenotypic similarity was also observed among the $\mathrm{J} 2$ and females of 33 M. graminicola populations from Nepal (Pokharel et al., 2007).

Molecular analysis of the M. graminicola populations from the Philippines revealed that molecular traits determined by the nuclear ribosomal DNA-ITS region were stable across all isolates. The same amplicon size was found in all M. graminicola isolates and there were no discernible differences in the nucleotide sequence. Based on the analysis of molecular diversity using this nuclear marker, these populations presented less interpopulation diversity than the ones observed in Vietnam (Bellafiore et al., 2015) and in Nepal (Pokharel et al., 2007). We could not conclude that all nuclear genetic traits were conserved across all isolates and, in order 


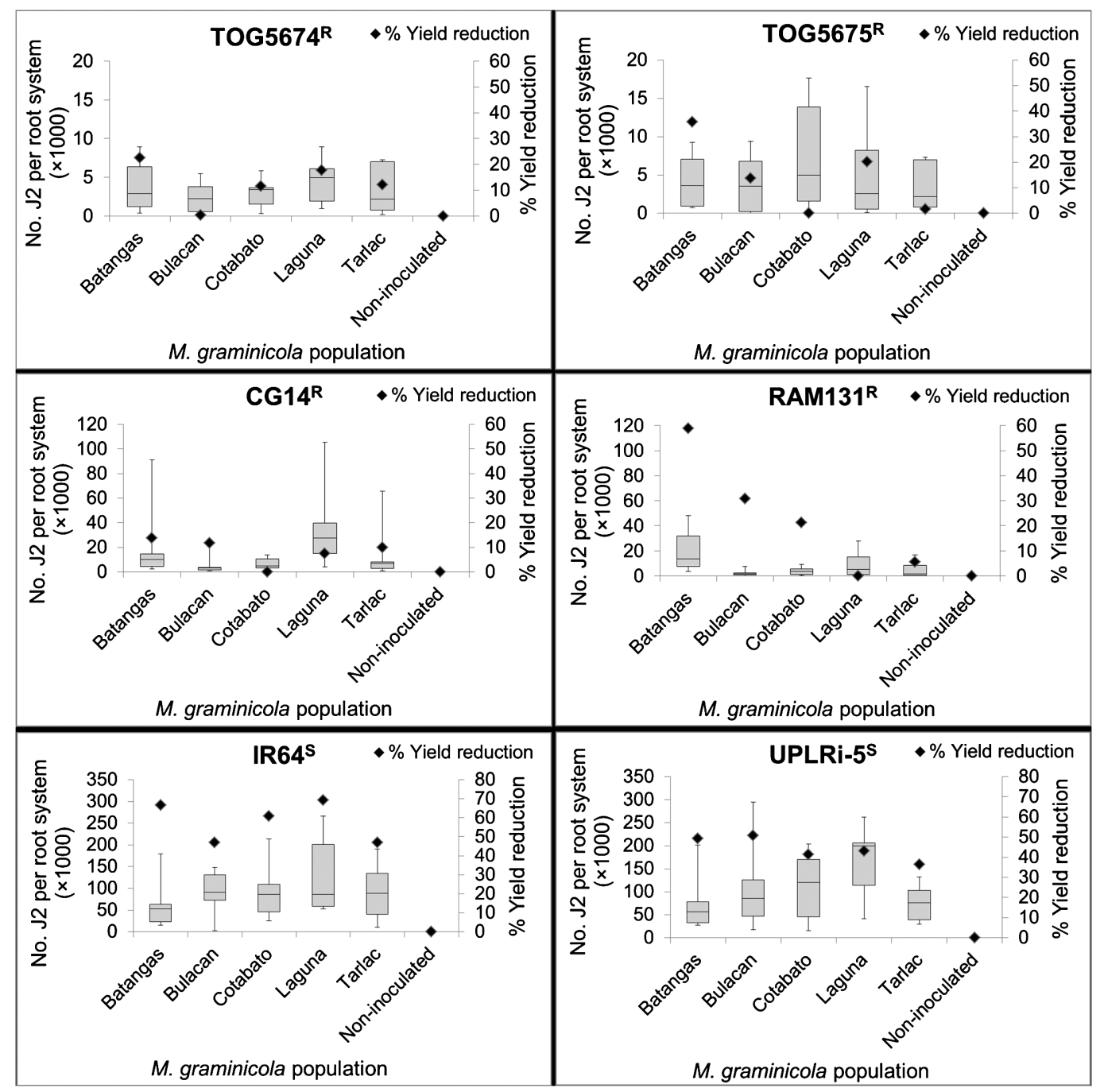

Fig. 3. Effect of the five Meloidogyne graminicola populations from the Philippines on the number of juveniles per root system and the yield reduction of four resistant $\left({ }^{\mathrm{R}}\right)$ and two susceptible $\left({ }^{\mathrm{S}}\right)$ rice genotypes grown in a sandy loam soil in the glasshouse. Number of nematodes initially inoculated $\left(P_{i}\right)$ : 6000 second-stage juveniles (J2) plant ${ }^{-1}$. Median boxplot with 25-75\% (boxes) and minimummaximum (error bars) values.

to address this question, other markers like microsatellites or single-nucleotide polymorphism (SNP) have to be developed. In the absence of information on the $M$. graminicola nuclear genome, we took advantage of the published mitochondrial genome to develop mitochondrial markers, as the polymorphism of mitochondrial DNA markers are known to be higher than that with nuclear markers from the genus Meloidogyne (HumphreysPereira \& Elling, 2013). From the three mtDNA markers used and covering up to 5000-bp (corresponding to $25 \%$ of the total mtDNA genome) few heteroplasmic sites were found. Only one of them, $\mathrm{mtMg}-2$, which includes the $5^{\prime}$ extremity of NAD4 and a non-coding region, presented six heteroplasmic sites. $\mathrm{mtMg}-1$ ( $3^{\prime} \mathrm{COX} 1$, a non-coding region and $5^{\prime} \mathrm{ND} 1$ ) and $\mathrm{mtMg}-3$ (tRNAS2, ATP6 and 5'ND5) were conserved between isolates and did not present heteroplasmic sites. This is in agreement with a previous study done on 15 populations from southern Europe on the dagger nematodes Xiphinema spp., where the molecular intraspecific diversity was studied using the $C O X 1$ gene. For example, a maximum of two heteroplasmic sites were found for $X$. pachtaicum 
in a 443-bp mitochondrial COX1 amplicon (GutiérrezGutiérrez et al., 2011). However, we did not find any heteroplasmic sites in the COXI gene, and we could only speculate that the molecular diversity at the intrapopulation level in M. graminicola in the Philippines was even lower than that of $X$. pachtaicum in southern Europe. Moreover, the molecular intraspecific diversity observed was very low compared to that observed in other Meloidogyne spp. (Humphreys-Pereira \& Elling, 2013). Hence, we could hypothesise that this genetic homogeneity in the $M$. graminicola populations in the Philippines reflects their predominant parthenogenetic reproduction mode and/or that these populations have experienced a similar colonisation history with probably a common ancestor.

The low variability in the morphometrics of $\mathrm{J} 2$ of the populations examined in this study can thus be accounted for by differences among individuals and not differences among populations. The molecular analysis of this study shows few differences in gene sequence of $\mathrm{J} 2$ belonging to the same $M$. graminicola population. Reproduction of the $M$. graminicola populations in resistant and susceptible varieties observed in this study indicates that the five $M$. graminicola populations have similar aggressiveness without any clear resistance-breaking populations.

The severity of root galling is a good indicator of virulence of a root-knot nematode species (Zhou et al., 2000; Anwar \& McKenry, 2007) and that is also the case for M. graminicola infection of rice. Root galls can limit the uptake of water and nutrients by the roots and their transportation inside the vascular cylinder of the roots. A great severity of root galling can thus cause considerable damage affecting plant growth and reducing yield. The study of De Waele et al. (2013) showed a significant correlation between the severity of root galling and yield of rice. On the two susceptible $O$. sativa varieties, all $M$. graminicola populations examined induced greater severity of root galling than $O$. glaberrima varieties. As a result, the yield of $O$. glaberrima varieties was much less reduced compared with the yield of $O$. sativa varieties, thus confirming the previous reports.

In only a minority of the instances (4 out of 36), infection with either of the five $M$. graminicola populations resulted in a significant percentage change in all nine plant growth and yield contributing traits measured of the inoculated $O$. glaberrima plants compared with the noninoculated control plants. However, in seven out of the 18 instances, infection with either of the five M. graminicola populations resulted in a significant percentage change in all nine plant growth and yield-contributing traits measured of the inoculated $O$. sativa plants compared with the non-inoculated control plants. Based on the low number of instances and the inconsistency of the effects of M. graminicola on the inoculated plants compared with the non-inoculated plants, one might be tempted to suggest that the five $M$. graminicola populations from the Philippines examined have no major differences in their effect on plant growth and grain production of rice varieties. However, this suggestion is not supported by a closer examination of the data of the effect of the different populations on filled grain weight per plant (yield). In two out of the four resistant $O$. glaberrima varieties included in this study, the Batangas population caused a significantly higher percentage yield reduction compared with the other M. graminicola populations. However, on $O$. sativa 'IR64', the Batangas population caused a significantly higher percentage yield reduction compared with two of the other M. graminicola populations while, in contrast, on the other $O$. sativa variety, 'UPLRi-5', the Batangas population caused a similar percentage yield reduction compared with all other M. graminicola populations. This observation may indicate that there are differences in virulence among the $M$. graminicola populations examined but we predict that these differences will be relatively minor. Nevertheless, this aspect should be further investigated and clarified.

Based on the results of this study, some of the plant traits of the $O$. sativa varieties measured are more reduced by $M$. graminicola infection than other ones. This is, for example, the case for fresh root weight, number of spikelets per panicle, fresh shoot weight and number of panicles per plant. Much reduction in these plant traits as a result of $M$. graminicola infection was also observed in the study of De Waele et al. (2013) in O. sativa 'IR64' and 'UPLRi-5' vs O. glaberrima 'CG14' and 'TOG5674'. Susceptible $O$. sativa varieties grown in raised beds in their study were reduced by $27.5 \%$ in fresh root weight, $31.4 \%$ in number of spikelets per panicle and $26.2 \%$ in number of panicles per plant when infected with $M$. graminicola. This indicates that $M$. graminicola can cause more damage to $O$. sativa genotypes than $O$. glaberrima varieties.

Based on the results of this study, some of the plant traits measured are less reduced by $M$. graminicola infection in the $O$. glaberrima varieties compared with the $O$. sativa varieties. The results of this study seems to 
confirm the observation by De Waele et al. (2013) carried out in raised beds that $O$. glaberrima varieties are not only resistant or less susceptible to $M$. graminicola but also less sensitive compared with $O$. sativa varieties. However, because the pathogen pressure per root unit $(1 \mathrm{~g})$ in this study was 3-5 times lower in the $O$. glaberrima varieties compared with the $O$. sativa varieties, it may also be possible that this difference in nematode susceptibility is the cause of the lower percentage yield reduction in the $O$. glaberrima varieties.

In this study, the number of tillers per plant was, on average, already much more reduced in the $O$. glaberrima varieties at 30 days after planting compared with the $O$. sativa varieties. This seems to contradict the previous suggestion that $O$. glaberrima varieties are less sensitive to $M$. graminicola infection than $O$. sativa varieties, but $O$. sativa varieties (such as 'IR64' and 'UPLRi-5') are known to have moderate to high tillering ability during the vegetative stage (Chang \& Loresto, 1986; Mahadevappa et al., 1991). As a result, infection with $M$. graminicola apparently does not reduce the number of tillers per plant in $O$. sativa as much as in $O$. glaberrima varieties. However, tillers of the $O$. sativa varieties were thinner compared with the $O$. glaberrima varieties, which had a higher tiller girth (data not shown) but which are known to be more prone to lodging (Futakuchi \& Sié, 2009).

All five M. graminicola populations from the Philippines examined in this study show a comparable and low virulence to the selected resistant $O$. glaberrima varieties and a high virulence to the selected susceptible $O$. sativa varieties. A high virulence on the susceptible rice genotypes may be due to an inherent compatibility of the M. graminicola populations with these varieties that, in turn, generates a highly virulent interaction, leading to a high nematode reproduction, plant damage and yield loss. Inherent incompatibility of the M. graminicola populations with the resistant rice varieties leads to both a low nematode reproduction and less damage and yield loss.

The assessment of variability in reproduction and pathogenicity of plant-parasitic nematode populations is important for the development of management strategies and decisions. Although only five M. graminicola populations were included in this study and one should be careful in generalising the observations of this study, the absence of variability in reproduction among the $M$. graminicola populations collected from five rice-producing regions differing in agro-ecology suggests that, at least in the
Philippines, the opportunity to use improved rice varieties with resistance to $M$. graminicola might be useful on a large scale (on the condition that this resistance can be introgressed from $O$. glaberrima into $O$. sativa varieties), but this may not be the case in other rice-growing regions. Resistance to nematodes in improved agricultural crop varieties may be durable if the target nematode species has a low level of genetic variability (Kaloshian et al., 1996) and thus also a low phenotypic variability. However, in Nepal, Pokharel et al. (2007) found a high and similar variability in aggressiveness among $33 \mathrm{M}$. graminicola populations measured on the basis of their severity of root galling and nematode reproduction on both a resistant ('Labelle') and susceptible Asian rice genotype ('LA 110'). The study of Pokharel et al. (2007) showed that 'Labelle', a previously known resistant rice variety (Yik \& Birchfield, 1979), was as susceptible to M. graminicola infection as 'LA 110'. So far, all indications are that the resistance to $M$. graminicola infection found in $O$. glaberrima varieties is constant, showing less variability (Soriano et al., 1999; De Waele pers. comm.). This (preliminary) observation may indicate that the resistance genes in $O$. glaberrima may be more durable and more useful in more rice-growing regions than the resistance genes in $O$. sativa. This is an observation that will need further examination to validate.

\section{Acknowledgements}

This research was supported by a Flemish Interuniversity Council (VLIR-UOS) Ph.D. scholarship to M.T.N.C. The authors would like to thank the International Rice Research Institute (IRRI) for the seeds, equipment and facilities and Luzviminda Fernandez, SergioVelasco and Juan Reyes for their technical assistance.

\section{References}

Anwar, S.A. \& McKenry, M.V. (2007). Variability in reproduction of four populations of Meloidogyne incognita on six cultivars of cotton. Journal of Nematology 39, 105-110.

Bellafiore, S., Jougla, C., Chapuis, E., Besnard, G., Soung, M., Vu, P.N., De Waele, D., Gantet, P. \& Thi, X.G. (2015). Intraspecific variability of the facultative meiotic parthenogenetic root-knot nematode (Meloidogyne graminicola) from rice fields in Vietnam. Comptes Rendus Biologies 338, 471483. DOI: 10.1016/j.crvi.2015.04.002

Berthou, F., Badiallo, A., Demaeyer, L., Deguiran, G., Bruguier, N. \& Dieng, M. (1989). Characterization of virulent (Mi- 
gene resistance breaking) biotypes of root-knot nematodes Meloidogyne Goeldi (Tylenchida) in two vegetable growing areas of Senegal. Agronomie 9, 877-884.

Besnard, G., Jühling, F., Chapuis, É., Zedane, L., Lhuillier, É., Mateille, T. \& Bellafiore, S. (2014). Fast assembly of the mitochondrial genome of a plant parasitic nematode ( $\mathrm{Me}$ loidogyne graminicola) using next generation sequencing. Comptes Rendus Biologies 337, 295-301. DOI: 10.1016/j. crvi.2014.03.003

Bos, L. \& Parlevliet, J.E. (1995). Concepts and terminology on plant/pest relationships: toward consensus in plant pathology and crop protection. Annual Review of Phytopathology 33, 69-102. DOI: 10.1146/annurev.py.33.090195.000441

Cabasan, M.T.N., Kumar, A. \& De Waele, D. (2012). Comparison of migration, penetration, development and reproduction of Meloidogyne graminicola on susceptible and resistant rice genotypes. Nematology 14, 405-415. DOI: 10.1163/ 156854111 X602613

Cabasan, M.T.N., Kumar, A., Bellafiore, S. \& De Waele, D. (2014). Histopathology of the rice root-knot nematode Meloidogyne graminicola on Oryza sativa and O. glaberrima. Nematology 16, 73-81. DOI: 10.1163/15685411-00002746

Carpenter, A.S. \& Lewis, S. (1991). Aggressiveness and reproduction of four Meloidogyne arenaria populations on soybean. Journal of Nematology 23, 232-238.

Castagnone-Sereno, P., Bongiovanni, M. \& Dalmasso, A. (1993). Stable virulence against the tomato resistance $M i$ gene in the parthenogenetic root-knot nematode Meloidogyne incognita. Phytopathology 83, 803-805. DOI: 10.1094/Phyto-83803

Chang, T.T. \& Loresto, G.C. (1986). Germplasm resource and breeding for drought resistance. In: Progress in upland rice research. Proceedings of the 1985 Jakarta conference. Manila, Philippines, International Rice Research Institute, pp. 199-202.

De Waele, D., Das, K., Zhao, D., Tiwari, R.K.S., Shrivastava, D.K., Vera-Cruz, C. \& Kumar, A. (2013). Host response of rice genotypes to the rice root-knot nematode (Meloidogyne graminicola) under aerobic soil conditions. Archives of Phytopathology and Plant Protection 46, 670-681. DOI: 10.1080/ 03235408.2012.749702

Dereeper, A., Guignon, V., Blanc, G., Audic, S., Buffet, S., Chevenet, F., Dufayard, J.F., Guindon, S., Lefort, V., Lescot, M. et al. (2008). Phylogeny.fr: robust phylogenetic analysis for the non-specialist. Nucleic Acids Research 36, 465-469. DOI: $10.1093 /$ nar/gkn180

Dropkin, V.H. (1988). The concept of race in phytonematology. Annual Review of Phytopathology 26, 145-161. DOI: 10. 1146/annurev.py.26.090188.001045

Eddaoudi, M., Ammati, M. \& Rammah, A. (1997). Identification of resistance breaking populations of Meloidogyne on tomatoes in Morocco and their effect on new sources of resistance. Fundamental and Applied Nematology 20, 285-289.
Futakuchi, K. \& Sié, M. (2009). Better exploitation of African rice (Oryza glaberrima Steud.) in varietal development for resource-poor farmers in west and central Africa. Agricultural Journal 4, 96-102.

Futakuchi, K., Jones, M.P. \& Ishi, R. (2001). Physiological and morphological mechanism of submergence resistance in African rice (Oryza glaberrima Steud.). Japanese Journal of Tropical Agriculture 45, 8-14. DOI: 10.11248/jsta1957.45.8

George, T., Magbanua, R., Garrity, D.P., Tubaña, B.S. \& Quiton, J. (2002). Rapid yield loss of rice cropped successively in aerobic soil. Agronomy Journal 94, 981-989. DOI: 10.2134/ agronj2002.0981

Golden, A.M. \& Birchfield, W. (1965). Meloidogyne graminicola (Heteroderidae), a new species of root-knot nematode from grass. Proceedings of the Helminthological Society of Washington 32, 228-231.

Gutiérrez-Gutiérrez, C., Castillo, P., Cantalapiedra-Navarrete, C., Landa, B.B., Derycke, S. \& Palomares-Rius, J.E. (2011). Genetic structure of Xiphinema pachtaicum and $X$. index populations based on mitochondrial DNA variation. Phytopathology 101, 1168-1175. DOI: 10.1094/PHYTO-07-100194

Hartman, K.M. \& Sasser, J.N. (1985). Identification of Meloidogyne species on the basis of differential host test and perineal pattern morphology. In: Barker, K.R., Carter, C.C. \& Sasser, J.N. (Eds). An advanced treatise on Meloidogyne. Vol. II, methodology. Raleigh, NC, USA, North Carolina State University Graphics, pp. 69-77.

Humphreys-Pereira, D.A. \& Elling, A.A. (2013). Intraspecific variability and genetic structure in Meloidogyne chitwoodi from the USA. Nematology 15, 315-327. DOI: 10.1163/ 15685411-00002684

Hussey, H. \& Janssen, G.J.W. (2002). Root-knot nematode: Meloidogyne species. In: Starr, J.L., Cook, R. \& Bridge, J. (Eds). Plant resistance to parasitic nematodes. Wallingford, UK, CAB International, pp. 43-70.

Jarguin-Barberena, H., Dalmasso, A.D.E., Guiran, G. \& Cardin, M.C. (1991). Acquired virulence in the plant parasitic nematode, Meloidogyne incognita. Biological analysis of the phenomenon. Revue de Nématologie 14, 299-303.

Jena, R.N. \& Rao, Y.S. (1977a). Nature of resistance in rice (Oryza sativa L.) to the root knot nematode (Meloidogyne graminicola) I. Mechanism of resistance. Proceedings of the Indian Academy of Science 86, 31-38.

Jena, R.N. \& Rao, Y.S. (1977b). Nature of resistance in rice (Oryza sativa L.) to the root knot nematode (Meloidogyne graminicola) II. Histopathology of nematode infection in rice varieties. Proceedings of the Indian Academy of Science 86, 87-91.

Jones, M.P., Dingkuhn, M., Aluko, G.K. \& Semon, M. (1997). Interspecific Oryza sativa L. $\times$ O. glaberrima Steud. progenies in upland rice improvement. Euphytica 92, 237-246. DOI: $10.1023 / \mathrm{A}: 1002969932224$ 
Kaloshian, I., Williamson, V.M., Miyao, G., Lawn, D.A. \& Westerdahl, B.B. (1996). "Resistance breaking" nematodes identified in California tomatoes. California Agriculture 50, 18-19. DOI: 10.3733/ca.v050n06p18

Kreye, C., Bouman, B.A.M., Reversat, G., Fernandez, L., Vera Cruz, C., Elazegui, F., Faronilo, J.E. \& Llorca, L. (2009). Biotic and abiotic causes of yield failure in tropical aerobic rice. Field Crops Research 112, 97-106. DOI: 10.1016/j.fcr. 2009.02.005

Mahadevappa, M., Rudraradhya, M., Shivappa, T.G. \& Panchaksharaiah, S. (1991). Performance of IR64 in Kamataka, India. International Rice Research Newsletter 4, 17.

Mulk, M.M. (1976). Meloidogyne graminicola. CIH Descriptions of plant-parasitic nematodes, Set 6, No. 87. Farnham Royal, UK, Commonwealth Agricultural Bureaux.

Netscher, C. (1976). Observations and preliminary studies on the occurrence of resistance breaking biotypes of Meloidogyne spp. on tomato. Cahiers ORSTOM, Série Biologie 11, 173178.

Noe, J.P. (1992). Variability among populations of Meloidogyne arenaria. Journal of Nematology 24, 404-414.

Olowe, T. (2010). Variation in virulence of Meloidogyne incognita race 1, 2, 3, and 4 on cowpea genotypes. European Journal of Scientific Research 43, 340-350.

Padgham, J.L., Duxbury, J.M., Mazid, A.M., Abawi, G.S. \& Hossain, M. (2004). Yield loss caused by Meloidogyne graminicola on lowland rainfed rice in Bangladesh. Journal of Nematology 36, 42-48.

Patil, J. \& Gaur, H.S. (2014). The effect of root-knot nematode, Meloidogyne graminicola, on the quality and vigour of rice seed. Nematology 1-10. DOI: 10.1163/15685411-00002787

Plowright, R.A., Coyne, D.L., Nash, P. \& Jones, M.P. (1999). Resistance to the rice nematodes Heterodera sacchari, Meloidogyne graminicola and M. incognita in Oryza glaberrima and $O$. glaberrima $\times O$. sativa interspecific hybrids. Nemato$\log y$ 1, 745-751. DOI: 10.1163/156854199508775

Pokharel, R.R., Abawi, G.S., Zhang, N., Duxbury, J.M. \& Smart, C.D. (2007). Characterization of isolates of Meloidogyne from rice-wheat production fields in Nepal. Journal of $\mathrm{Ne}$ matology 39, 221-230.

Pokharel, R.R., Abawi, G.S., Duxbury, J.M., Smart, C.D., Wang, X. \& Brito, J.A. (2010). Variability and the recognition of two races in Meloidogyne. Australasian Plant Pathology 39, 326333. DOI: 10.1071/AP09100

Prot, J.-C. (1984). A naturally occurring resistance breaking biotype of Meloidogyne arenaria on tomato. Reproduction and pathogenicity on tomato cultivars Roma and Rossol. Revue de Nématologie 7, 23-28.

Reversat, G. \& Fernandez, L. (2004). Effect of inoculations with single and multiple juveniles on release of progeny of Meloidogyne graminicola from susceptible rice. Nematology 6, 1-6. DOI: 10.1163/156854104323072856

Reversat, G., Boyer, J., Sannier, C. \& Pando-Bahuon, A. (1999). Use of a mixture of sand and water-absorbent synthetic polymer as substrate for the xenic culturing of plant-parasitic nematodes in the laboratory. Nematology 1, 209-212. DOI: $10.1163 / 156854199508027$

Roberts, P. \& Thomason, J. (1986). Variability in reproduction of isolates of $M$. incognita and $M$. javanica on resistant tomato genotypes. Plant Disease 70, 547-551. DOI: 10.1094/PD-70547

Roberts, P.A., Dalmasso, A., Cap, G.B. \& Castagnone-Sereno, P. (1990). Resistance in Lycopersicon peruvianum to isolates of $\mathrm{Mi}$ gene compatible Meloidogyne populations. Journal of Nematology 22, 585-589.

Sarla, N. \& Swamy, B.P.M. (2005). Oryza glaberrima: a source for the improvement of Oryza sativa. Current Science 89, 955-963.

Seinhorst, J.W. (1950). De betekenis van de toestand van de grond voor het optreden van aantasting door het stengelaaltje (Ditylenchus dipsaci (Kühn) Filipjev). Tijdschrift over Plantenziekten 56, 288-348.

Semblat, J.P., Bongiovanni, M., Wajnberg, E., Dalmasso, A., Abad, P. \& Castagnone-Sereno, P. (2000). Virulence and molecular diversity of parthenogenetic root-knot nematodes, Meloidogyne spp. Heredity 84, 81-89. DOI: 10.1046/j.13652540.2000.00633.x

Soriano, I.R., Schmit, V., Brar, D.S., Prot, J. \& Reversat, G. (1999). Resistance to rice root-knot nematode Meloidogyne graminicola identified in Oryza longistaminata and O. glaberrima. Nematology 1, 395-398. DOI: 10.1163/ 156854199508397

Soriano, I.R., Prot, J. \& Matias, D.M. (2000). Expression of tolerance for Meloidogyne graminicola in rice cultivars as affected by soil type and flooding. Journal of Nematology 32, 309-317.

Tamura, K., Stecher, G., Peterson, D., Filipski, A. \& Kumar, S. (2013). MEGA6: molecular evolutionary genetics analysis version 6.0. Molecular Biology and Evolution 3, 2725-2729. DOI: 10.1093/molbev/mst197

Triantaphyllou, A.C. (1985). Cytogenetics, cytotaxonomy and phylogeny of root-knot nematodes. In: Sasser, J.N. \& Carter, C.C. (Eds). An advance treatise on Meloidogyne. Vol. I, biology and control. Raleigh, NC, USA, North Carolina State University Press, pp. 113-126.

van der Beek, J.G., Maas, P.W.T.H., Janseen, G.J., Zijistra, C. \& Van Silfhout, C.H. (1999). A pathotype to describe intraspecific variation in pathogenicity of Meloidogyne chitwoodi. Journal of Nematology 31, 386-392.

Wade, L.J., McLaren, C.G., Quintana, L., Harnpichitvitaya, D., Rajatasereekul, S., Sarawgi, A.K., Kumar, A., Ahmed, H.U., Singh Sarwoto, A.K., Rodriguez, R. et al. (1999). Genotype by environment interactions across diverse rainfed lowland rice environments. Field Crops Research 64, 35-50.

Win, P.P., Kyi, P.P., Maung, Z.T.Z. \& De Waele, D. (2013). Evaluation of the host response of lowland and upland rice varieties from Myanmar to the rice root-knot nematode Meloidogyne graminicola. Archives of Phytopathology and 
Plant Protection 47, 869-891. DOI: 10.1080/03235408.2013. 824640

Wu, J.-L., Wu, C., Lei, C., Baraoidan, M., Bordeos, A., Madamba, M.R.S., Ramos-Pamplona, M., Mauleon, R., Portugal, A., Ulat, V.J. et al. (2005). Chemical- and irradiationinduced mutants of indica rice IR64 for forward and reverse genetics. Plant Molecular Biology 59, 85-97.
Yik, C.P. \& Birchfield, W. (1979). Host studies and reactions of cultivars to Meloidogyne graminicola. Phytopathology 69, 497-499.

Zhou, E., Wheeler, T.A. \& Starr, J.L. (2000). Root galling and reproduction of Meloidogyne incognita isolates from Texas on resistant cotton genotypes. Journal of Nematology (Supplement) 32, 513-518. 